\title{
Evaluation of Global Water Resources Reanalysis Products in the Upper Blue Nile River Basin
}

\author{
MARIKA KOUKOULA \\ Department of Civil and Environmental Engineering, University of Connecticut, Storrs, Connecticut \\ EFTHYMIOS I. NIKOLOPOULOS \\ Department of Civil and Environmental Engineering, University of Connecticut, Storrs, Connecticut, and \\ Department of Mechanical and Civil Engineering, Florida Institute of Technology, Melbourne, Florida

\section{ZOI DOKOU} \\ Department of Civil and Environmental Engineering, University of Connecticut, Storrs, Connecticut, and \\ Department of Civil Engineering, California State University, Sacramento, California

\section{EMMANOUIL N. ANAGNOSTOU} \\ Department of Civil and Environmental Engineering, University of Connecticut, Storrs, Connecticut
}

(Manuscript received 30 September 2019, in final form 3 March 2020)

\begin{abstract}
Water resources reanalysis (WRR) can be used as a numerical tool to advance our understanding of hydrological processes where in situ observations are limited. However, WRR products are associated with uncertainty that needs to be quantified to improve usability of such products in water resources applications. In this study, we evaluate estimates of water cycle components from 18 state-of-the-art WRR datasets derived from different land surface/hydrological models, meteorological forcing, and precipitation datasets. The evaluation was conducted at three spatial scales in the upper Blue Nile basin in Ethiopia. Precipitation, streamflow, evapotranspiration (ET), and terrestrial water storage (TWS) were evaluated against in situ daily precipitation and streamflow measurements, remote sensing-derived ET, and the NASA Gravity Recovery and Climate Experiment (GRACE) product, respectively. Our results highlight the current strengths and limitations of the available WRR datasets in analyzing the hydrological cycle and dynamics of the study basins, showing an overall underestimation of ET and TWS and overestimation of streamflow. While calibration improves streamflow simulation, it results in a relatively poorer performance in terms of ET. In addition, we show that the differences in the schemes used in the various land surface models resulted in significant differences in the estimation of the water cycle components from the respective WRR products, while we noted small differences among the products related to precipitation forcing. We did not identify a single product that consistently outperformed others; however, we found that there are specific WRR products that provided accurate representation of a single component of the water cycle (e.g., only runoff) in the area.
\end{abstract}

\section{Introduction}

Population growth is associated with increasing demands on water, food, and energy, with uncertain future trajectories due to climate change. This has intensified the need for sustainable freshwater resources management,

Corresponding author: Emmanouil Anagnostou, manos@ uconn.edu which, in turn, requires a sufficient understanding of the hydrological cycle at river basin scale. Traditionally, in situ hydrological observations have been the main source of data on key components of the water cycle, including precipitation, runoff, soil moisture, and groundwater. Many developing countries, however, lack in situ data, or the records from their water observational networks are incomplete (Grabs 2009). Model-based water resources reanalysis (WRR) provides an alternative 
means to advance understanding of hydrological processes in these data-poor regions, but these products are also associated with uncertainty related to errors in the forcing data (Getirana et al. 2011; Fekete et al. 2004) and parameterizations of the physical processes in the modeling schemes involved (Yen et al. 2014; Jankov et al. 2005). Understanding this uncertainty and quantifying its impact on WRR is, therefore, imperative for advancing the application of these products to water resources (Schellekens et al. 2017; Beck et al. 2017).

The African continent is generally characterized by sparse hydrological observations, while, at the same time, it is in need of efficient management of available freshwater resources to enhance food and water security. In particular, this study focuses on the upper Blue Nile (UBN) river basin, due to the transboundary role of the basin. Accounting for about $60 \%$ of the river's annual flow (Conway 2005), the basin supplies water to hundreds of millions of people living within the area and downstream nations (Sudan and Egypt).

The numerous hydrological studies focusing on UBN cover either the entire basin (Gebremicael et al. 2013) or small subbasins (Rientjes et al. 2011; Uhlenbrook et al. 2010). Most have used in situ observations (Taye and Willems 2011), remote sensing data (Teferi et al. 2010; Abera et al. 2017), or outputs of hydrological models (Tegegne et al.2017) to examine specific components of the hydrological cycle, such as rainfall (Mokria et al. 2017), evapotranspiration (ET; Allam et al. 2016), or water storage (Shamsudduha et al. 2017). Only a few have focused on the water budget in the area (Tekleab et al. 2011; Siam et al. 2013; Jung et al. 2017). Abera et al. (2017) used the JGrass-NewAGE system and various remote sensing products to estimate precipitation, ET, discharge, and storage in UBN. Their analysis showed precipitation is around $1360 \pm 230 \mathrm{~mm} \mathrm{yr}^{-1}$, with the average basin-scale ET at about $740 \pm 87 \mathrm{~mm} \mathrm{yr}^{-1}$ (constituting about $56 \%$ of the annual budget) and the long-term annual runoff at about $454 \pm 160 \mathrm{~mm} \mathrm{yr}^{-1}$. Siam et al. (2013) used atmospheric and soil water balance constraints to evaluate general circulation models (GCMs) and the ability of reanalysis products to simulate the hydrological cycle in the basin. They found that most GCMs overestimate the hydrological cycle fluxes (i.e., associated with higher precipitation, runoff, and ET) relative to observations, and they observed some improvement in the simulated hydrological cycle with increased horizontal resolution. Little knowledge exists, however, with regard to the representation of all the components of the hydrological cycle, which is now possible through use of globally available WRR products. These allow, at the very least, an adequate characterization of hydrological fluxes (precipitation, streamflow, and
ET) and states (soil moisture) at monthly and annual scale.

In this study, we present a comprehensive evaluation and comparison of water cycle components in UBN, derived from state-of-the-art water resources reanalysis products, which were derived from different land surface models (LSMs) and hydrological models, meteorological forcings, and precipitation datasets at three basin scales. The objective of our study was to evaluate the uncertainty (associated with the spread of the datasets) in the estimation of water cycle components, with the purpose of providing essential information for the use of these data in water resources management, as well as feedback to model developers for future improvements. Agriculture is a predominant sector of the economy of Ethiopia, and the Blue Nile basin in particular; therefore, water resource development projects for irrigation are very important. Moreover, UBN is part of a transboundary river; therefore, quantitative information about the variability of the basin's water cycle components and its association with climate forcing can support water diplomacy. Furthermore, the sustainable water resources management depends on knowledge of water cycle variability and dynamics, provided by these WRR datasets. Understanding the strengths and limitations of these datasets is therefore essential for identifying their appropriate use for different water resources applications and decision-making. To this end, we evaluated WRR datasets produced through NASA's Land Data Assimilation System (LDAS) over East Africa (https://disc.gsfc.nasa.gov/ datasets?keywords $=$ FLDAS) and the latest version (tier 2) of the global WRR products of the European Union's "eartH2Observe" project (hereinafter WRR2; https:// wci.earth2observe.eu/). We evaluated precipitation, ET, streamflow, and terrestrial water storage (TWS) against, respectively, daily precipitation from in situ rain gauge measurements, remote sensing-derived ET (Zhang et al. 2009, 2010, 2015), in situ streamflow measurements, and water storage deviations from the NASA Gravity Recovery and Climate Experiment (GRACE) product (Wahr and Zhong 2013; Swenson et al. 2008).

This paper is organized into six sections. The next section introduces the characteristics of the study area. Section 3 briefly describes the observation and reanalysis datasets we used, and section 4 presents the method we adopted for the analysis. The main results of the evaluation and the water budget analysis appear in section 5; section 6 discusses our main findings and summarizes our conclusions.

\section{Study area}

As stated in the introduction, the region under consideration is the area of UBN (Fig. 1). The analysis has 


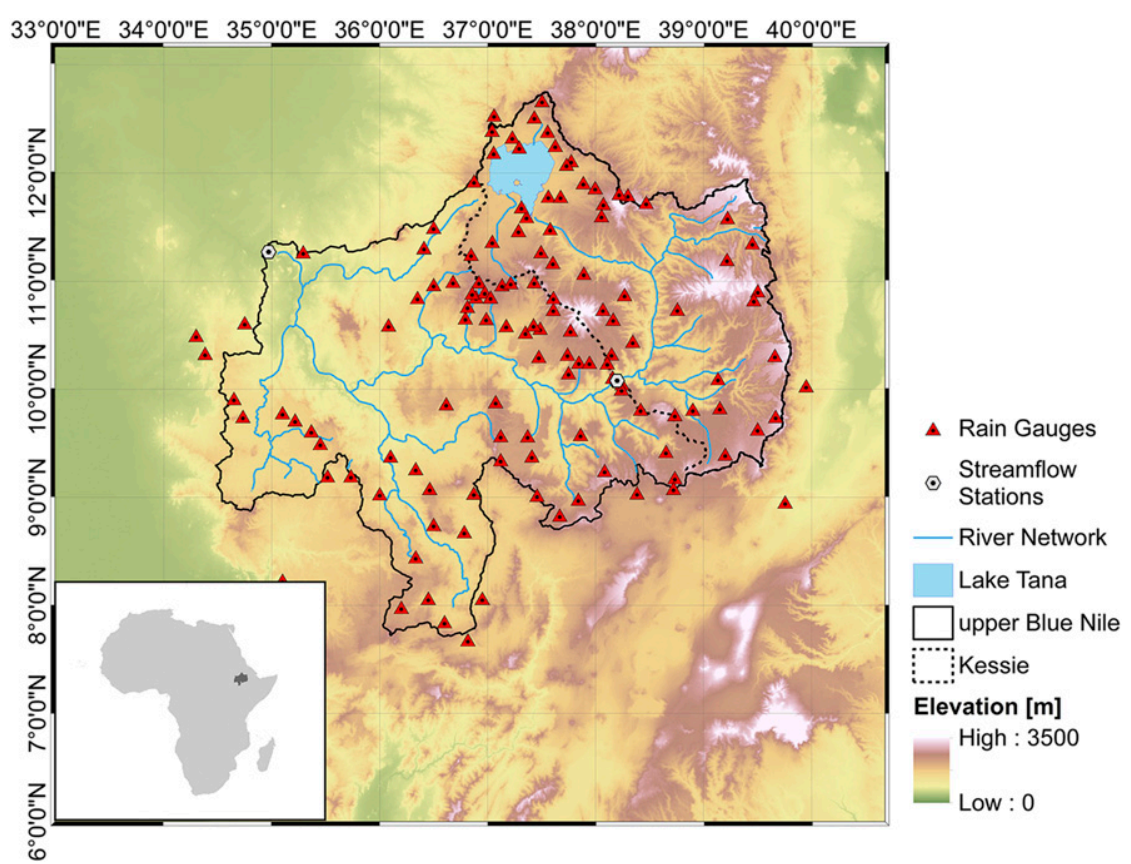

FIG. 1. Study area of the upper Blue Nile $\left(177643 \mathrm{~km}^{2}\right)$ and the Kessie $\left(50418 \mathrm{~km}^{2}\right)$ basins, with rain gauge and streamflow station locations and river network.

been carried out at three spatial scales: the entire UBN; the Kessie basin, which is located at the northeastern part of the UBN; and the downstream, wetter part of the UBN basin [downstream (D/S) Kessie]. The hydrology of UBN has a significant role in the region, being the headwaters of the Blue Nile River that provides water security to Sudan and Egypt. The basin is $177000 \mathrm{~km}^{2}$ in size, with highly varied topography. Elevations range from more than $4000 \mathrm{~m}$ in the Ethiopian highlands (at the eastern part of the basin) to about $500 \mathrm{~m}$ in the lowlands along the Ethiopia-Sudan border (at the western part). The basin's land cover includes $37.2 \%$ agriculture, $30.3 \%$ grassland and/brushland, and $1.96 \%$ water (Melesse et al. 2011), and Lake Tana, with a surface area of $3156 \mathrm{~km}^{2}$, is located in its northwestern part.

The climate of the UBN basin varies from humid to semiarid, and its precipitation is highly seasonal. The main seasons are dry (from October to May) and wet (from June to September), when about $70 \%$ of the precipitation occurs (Conway 2000). The interannual variability of precipitation in the wet season is correlated with El Niño-Southern Oscillations (Siam and Eltahir 2015). More specifically, Eltahir (1996) found that $25 \%$ of the natural variability in the annual flow of the Nile is associated with El Niño oscillation. Rainfall over the basin varies significantly and follows a distinct pattern, with highest accumulation $\left(\sim 160 \mathrm{~mm} \mathrm{month}^{-1}\right)$ in its southwestern part (D/S Kessie) and lowest $\left(\sim 85 \mathrm{~mm} \mathrm{month}^{-1}\right)$ in the northeast (Kessie) (Fig. 2).
This high spatial variability of precipitation was the main reason we chose to conduct the analysis in the three basins mentioned above.

\section{Datasets}

We analyzed WRR datasets produced through NASA's Famine Early Warning Systems Network (FEWS NET) Land Data Assimilation System (FLDAS) (McNally et al. 2017), at regional (East Africa) scale; and from the latest

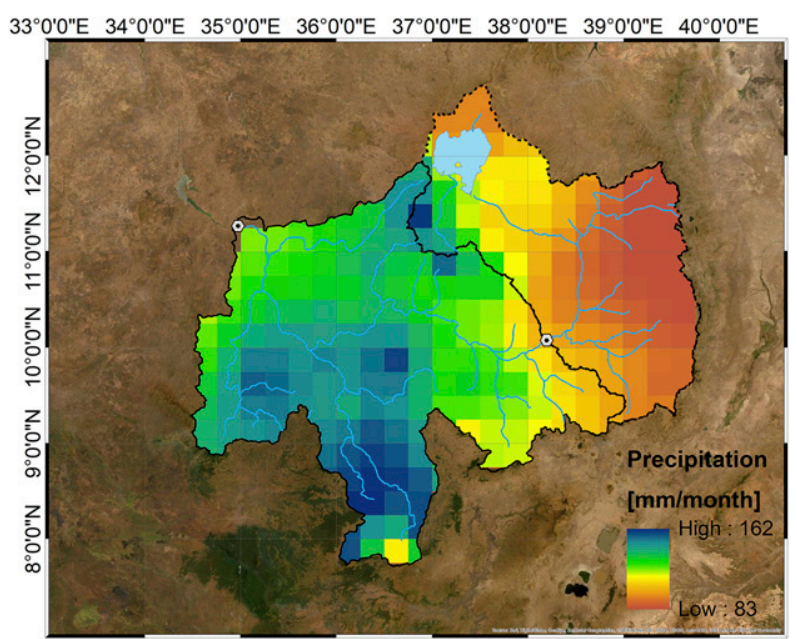

FIG. 2. Mean annual precipitation (mm month $\left.{ }^{-1}\right)$ from 1984 to 2013 from interpolated rain gauge observations. 
version (tier 2) of the global WRR product of the European Union's WRR2 (Schellekens et al. 2017). For each dataset, different LSM and hydrological models, precipitation forcing, and spatial resolution have been used, as described in Table 1 .

The FLDAS is a multimodel and multiforcing system that simulates hydroclimate states and fluxes over Africa. The precipitation forcing for the FLDAS data is the temporal downscaled Climate Hazards Group Infrared Precipitation with Station (CHIRPS) dataset (McNally et al. 2017), which is an IR-based rainfall product that has been bias corrected with monthly station climatologies (Funk et al. 2015). The other meteorological forcing variables are based on NASA's Modern-Era Retrospective Analysis for Research and Applications, version 2.0 (MERRA-2), product (Bosilovich et al. 2015). The two WRR products from the FLDAS system that we used in this study are derived from two different models, the Variable Infiltration Capacity (VIC), version 4.1.2, model, which is a spatially distributed macroscale hydrology model (Liang et al. 1994), and the Noah Land Surface Model (Ek et al. 2003), version 3.3, which is a four-soil-layer water and energy balance LSM. For these simulations, VIC is calibrated against observations.

The WRR2 dataset is a multimodel ensemble generated by 10 global hydrological and land surface models. The precipitation datasets used as forcing for these models are the Multi-Source WeightedEnsemble Precipitation (MSWEP) dataset (Beck et al. 2017), a blended product derived from atmospheric reanalysis combined with satellite precipitation and in situ observed data; and two satellite-precipitation datasets: the Tropical Rainfall Measuring Mission (TRMM) product and the Climate Precipitation Center morphing technique (CMORPH) dataset. The meteorological forcing variables required for the hydrological simulations were derived from ERA-Interim 3-hourly data (Balsamo et al. 2015), bilinearly interpolated to $0.25^{\circ}$.

In this study, we also used simulations from four land surface models-JULES (Joint U.K. Land Environment Simulator) (Best et al. 2011; Clark et al. 2011); ORCHIDEE (Organizing Carbon and Hydrology in Dynamic Ecosystems) (Krinner et al. 2005); SURFEX (Surface Externalisée) (Masson et al. 2013); and HTESSEL (Hydrology Tiled ECMWF Scheme for Surface Exchanges over Land) (Balsamo et al. 2009)—and two global hydrological models: the distributed global hydrological model of the WaterGAP3 (Water-Global Assessment and Prognosis) modeling framework (Flörke et al. 2013; Döll et al. 2009) and the LISFLOOD distributed water balance and flood simulation model (Burek et al. 2013). WaterGAP3 is

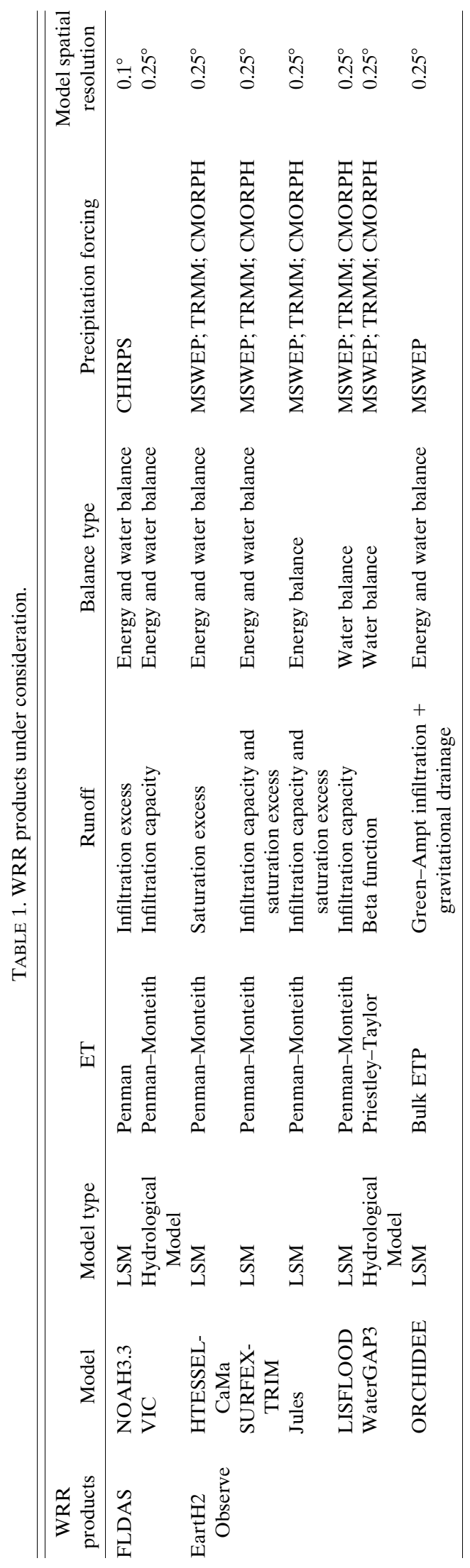




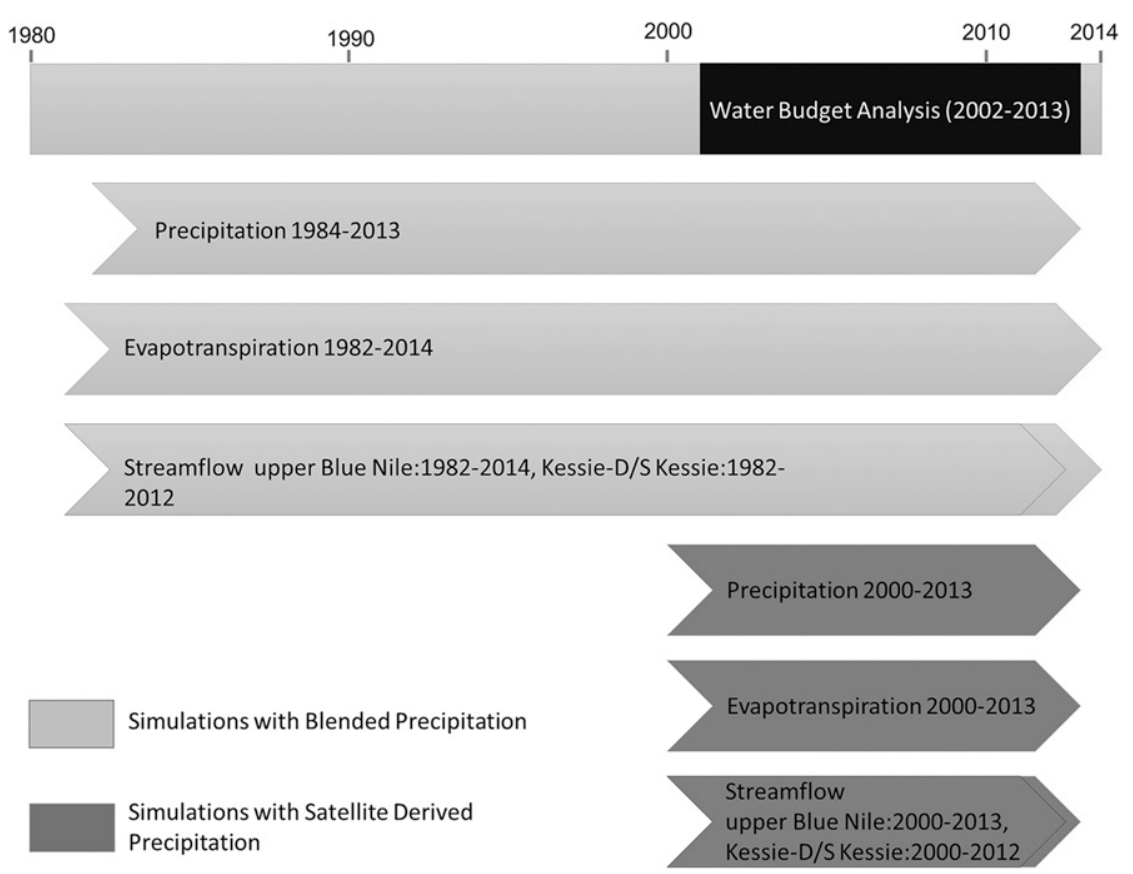

FIG. 3. Schematic representation of the temporal extent of the evaluation.

calibrated and validated against measured river discharge from stations of the Global Runoff Data Centre data repository (Schellekens et al. 2017). All models were forced with the three precipitation datasets described above (MSWEP, TRMM, and CMORPH).

To evaluate the precipitation datasets used as forcing for the models, we used the gridded precipitation products derived by spatial interpolated daily precipitation measurements from 153 in situ rain gauges (Fig. 1) provided by the Ethiopian National Meteorological Agency (Sahlu et al. 2016). For ET, we used as reference the remote sensing-derived actual ET at $(1 / 12)^{\circ}$ spatial resolution (Zhang et al. 2010). For this product, a satellite remote sensing-based ET algorithm was applied. The algorithm quantifies canopy transpiration and soil evaporation using a modified Penman-Monteith approach with biome-specific canopy conductance determined from the normalized difference vegetation index (NDVI) and quantifies open water evaporation using a Priestley-Taylor approach. For the evaluation of the streamflow simulations from the models, we used daily in situ streamflow observations provided by the Ministry of Water, Irrigation, and Energy and the Abbay Basin Authority. Last, we evaluated TWS estimates against the NASA Jet Propulsion Laboratory (JPL) RL05M.1 GRACE Mascon Solution product. The GRACE data are global observations of surface mass changes with a spatial sampling of $0.5^{\circ}$ in both latitude and longitude.

\section{Method}

To quantify the uncertainty in the estimation of the water cycle components over the UBN basin, we conducted a comprehensive evaluation and comparison of the 18 different reanalysis products described above. We separated the WRR data into two groups; the first included the products with blended precipitation data forcing and the second those with satellite-derived precipitation (TRMM and CMORPH) forcing, and we compared precipitation, ET, and streamflow against observations. We conducted the evaluation over three basin scales, that of the UBN $\left(177643 \mathrm{~km}^{2}\right)$, the relatively dry Kessie basin $\left(50418 \mathrm{~km}^{2}\right)$, and the wetter downstream part of the UBN basin (D/S Kessie) $\left(127225 \mathrm{~km}^{2}\right)($ Fig. 1) at a monthly temporal scale. The period of the evaluation depended on the availability of the reference data. Figure 3 presents a schematic representation of the temporal extent of the evaluation for the different variables over the three basins.

We assessed the performance of the WRR products using relative error (RE) calculated as

$$
\mathrm{RE}=\frac{\mathrm{SIM}-\mathrm{OBS}}{\overline{\mathrm{OBS}+\mathrm{SIM}}}
$$

where SIM is the monthly simulated data (shown in Table 1) and OBS is the monthly observation data for each water cycle variable. Additional information about the relative skill of each WRR product is provided through 
normalized Taylor diagrams (Taylor 2001; Kärnä and Baptista 2016), which combine the correlation coefficient (COR), centered root-mean-square error (CRMSE), and standard deviation (SD) of the modeled and observed fields in one plot. In the normalized Taylor diagram, the results (COR, CRMSE, and SD) are normalized by the reference variables; the perfect model always lies at $(r=$ $1, \theta=0)$. The CRMSE is calculated as

$$
\mathrm{CRMSE}=\sqrt{\frac{\sum_{i=1}^{N}[(\mathrm{OBS}-\overline{\mathrm{OBS}})-(\mathrm{SIM}-\overline{\mathrm{SIM}})]^{2}}{N},}
$$

where $N$ is the number of observations and simulated data (number of months).

To understand how different LSMs represent the annual variations in water budget components-precipitation, ET, streamflow, and TWS - and the overall hydrological regime of the basin, we performed a water budget analysis over the two basins for the period 2002-13. For this analysis we calculated the mean relative error (MRE) for each of the hydrological cycle variables as

$$
\text { MRE }=\overline{\left(\frac{\mathrm{SIM}-\mathrm{OBS}}{\mathrm{OBS}}\right)},
$$

where here SIM is now the annual estimates of the variables under consideration derived from the models and OBS is the annual observations for each variable.

We calculated the changes in the TWS estimates at monthly scale using an equation adapted for watersheds (Zeng et al. 2008; Hirschi et al. 2006):

$$
\operatorname{TWSC}(t)=\int[P(t)-\mathrm{ET}(t)-Q(t)] d t
$$

where TWSC is the change of TWS, $P$ is precipitation, ET is evapotranspiration, and $Q$ is streamflow (at monthly scale).

To compare the TWS estimates with those from the GRACE product, we calculated the TWS anomalies for each grid point by averaging the values in each grid point over the 2002-13 baseline and subtracting that value from all time steps. The area of the UBN basin is close to the minimum area that can be resolved by GRACE (which ranges from $200000 \mathrm{~km}^{2}$ at low latitudes to $90000 \mathrm{~km}^{2}$ near the poles) (Rodell et al. 2018). As this is not the case for the Kessie and the wetter basin, however, we expected errors and uncertainties to be larger at these scales.

Also, for the TWS evaluation at monthly scale, we calculated the COR, the relative standard deviation (RSD), and the root-mean-square error (RMSE) as

$$
\begin{aligned}
\mathrm{COR} & =\frac{1}{N-1} \sum_{i=1}^{N}\left(\frac{\overline{\mathrm{OBS}-\overline{\mathrm{OBS}}}}{\sigma_{\mathrm{OBS}}}\right)\left(\frac{\mathrm{SIM}-\overline{\mathrm{SIM}}}{\sigma_{\mathrm{SIM}}}\right), \\
\mathrm{RSD} & =\sigma_{\mathrm{SIM}}^{2} / \sigma_{\mathrm{OBS}}^{2}, \text { and } \\
\mathrm{RMSE} & =\sqrt{\frac{\sum_{i=1}^{N}(\mathrm{OBS}-\mathrm{SIM})^{2}}{N}},
\end{aligned}
$$

where $\sigma$ is the standard deviation and $\sigma^{2}$ is the variance.

Last, we conducted an imbalance analysis to assess the uncertainties of the datasets used as reference for this study. At the basin scale the different hydrological components of the hydrological cycle should close the water budget, and the water budget equation should be satisfied:

$$
P-\mathrm{ET}-Q-\Delta \mathrm{TWS}=0 .
$$

We estimated the water budget residual at monthly scale (i.e., the quantity $P-\mathrm{ET}-Q-\Delta \mathrm{TWS}$ ) using the reference datasets.

\section{Results}

We begin our presentation of the results of the WWR products error analysis with statistical evaluation of the estimation of water cycle components by the different reanalysis products, followed by a water budget analysis at three spatial scales in UBN.

One of the most important components that drives the variability of the water cycle is precipitation. Figures $4 \mathrm{a}$ and $4 \mathrm{~b}$ show the distribution of the relative errors of the monthly, basin-averaged precipitation data, which was used as forcing for the LSM and hydrological models. We noted that all products obtained lower relative errors over the wetter part of the UBN basin than over the smaller (drier) one. Moreover, as is evident from the figure, the median of MSWEP (0.002 in the entire UBN, -0.055 in Kessie, and -0.0461 in D/S Kessie) and TRMM $(-0.03$ in the UBN, -0.081 in Kessie, and -0.0540 in $\mathrm{D} / \mathrm{S}$ Kessie) obtained the closest agreement with the observations over the three basins. For the entire UBN and the wetter region (D/S Kessie), however, the width of the distribution for CHIRPS decreased (compared to the other datasets), which implies lower uncertainty. For the smaller basin, TRMM obtained the lower uncertainty. To the contrary, CMORPH was associated with the highest relative errors in all three basins - up to 0.55 in the drier region for the 75 th percentile and -0.35 for the 25 th percentile in the wet region.

The relative errors of the basin-averaged, monthly ET, and streamflow estimates from the WRR products 


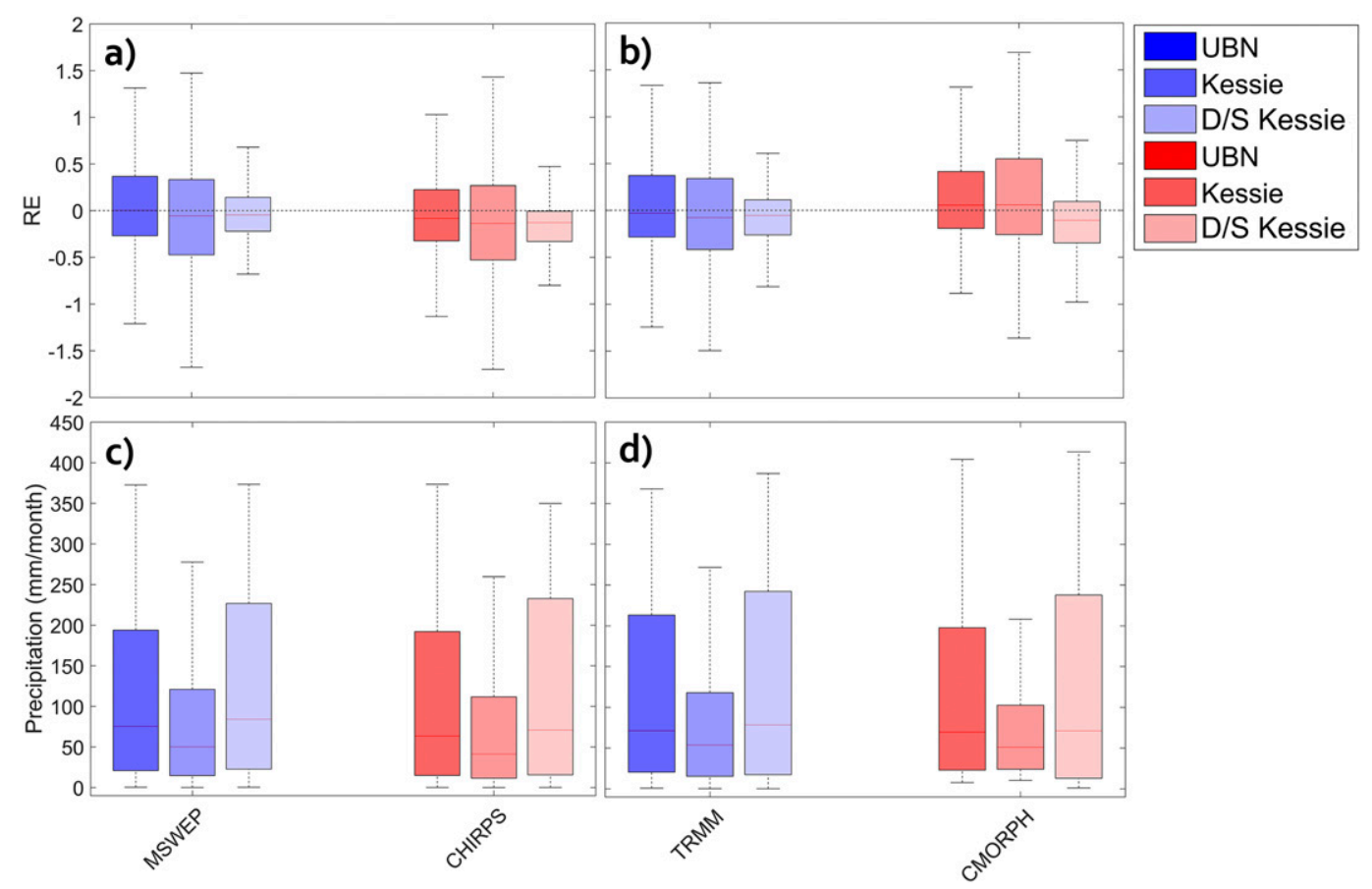

FIG. 4. Boxplots of precipitation (a),(b) relative errors and (c),(d) monthly values $\left(\mathrm{mm} \mathrm{month}{ }^{-1}\right.$ ) for products with (left) reanalysis- and (right) satellite-derived precipitation forcing.

are shown in Figs. 5 and 6, respectively. The bias for ET was slightly higher than that for precipitation, but the uncertainty was lower in most of the models. A point to note from Fig. 5 is the overall underestimation of ET at all basin scales. Furthermore, although the differences among the datasets produced with the same LSM or hydrological model and different precipitation forcings were relatively small, we observed that WRR with blended precipitation forcing (MSWEP and CHIRPS) represented ET slightly better than the satellite-derived precipitation-forced WRR products in terms of RE. Specifically, HTESSEL-CaMa forced with MSWEP achieved the lowest relative errors for both basins (with a median of -0.26 in the entire UBN, -0.15 in Kessie, and -0.22 in the wetter region of the UBN basin), and WaterGAP3 forced with CMORPH had the highest bias (with a median of -0.28 in the entire UBN, -0.47 in Kessie, and -0.13 in $\mathrm{D} / \mathrm{S}$ Kessie). The median of the REs for VIC was very low (0.094 in the entire UBN, -0.1 in Kessie, and 0.19 in D/S Kessie); however, the spread of the distribution was higher than that of other models. Similar spread of distribution was evident for WaterGAP3 and Noah models, which exhibited higher uncertainty. Most of the products achieved better performance for ET over the drier region (Kessie basin) than over the wetter region.

The relative errors of the streamflow estimates (Fig. 6) were much higher than those of ET and precipitation.
In some cases, the 75th percentile of the REs was close to (i.e., with LISFLOOD and JULES) or more than (ORCHIDEE) 1.5 (mainly in the wetter region). Here, as for ET, most products obtained lower relative errors over the drier (smaller) basin than the wetter one. There was, overall, an overestimation of streamflow in the wetter region of the UBN. Also notable in Fig. 6 is that, in this case, most of the WRR products with TRMM (satellite derived) precipitation achieved a better representation of streamflow than those derived from the same models and different precipitation forcing. WaterGAP3 forced with TRMM obtained the closest agreement with the streamflow observations in the entire UBN basin (and the wetter region), with a low bias (median of 0.133 ) and the lowest uncertainty compared to the other models. HTESSEL-CaMa had the best representation of streamflow in the small (drier) basin in terms of RE (with a median of -0.035 with CMORPH forcing).

Figures 7 and 8 show normalized Taylor diagrams, which are used to demonstrate the relative skill of the WRR products in representing the water cycle components. As mentioned above, all precipitation data were in close agreement with observations, in terms of both correlation and variance. CHIRPS and TRMM exhibited the best performance in the wet (D/S Kessie) and dry (Kessie) basins, respectively, obtaining the highest correlation ( 0.98 and 0.95 , respectively) and 


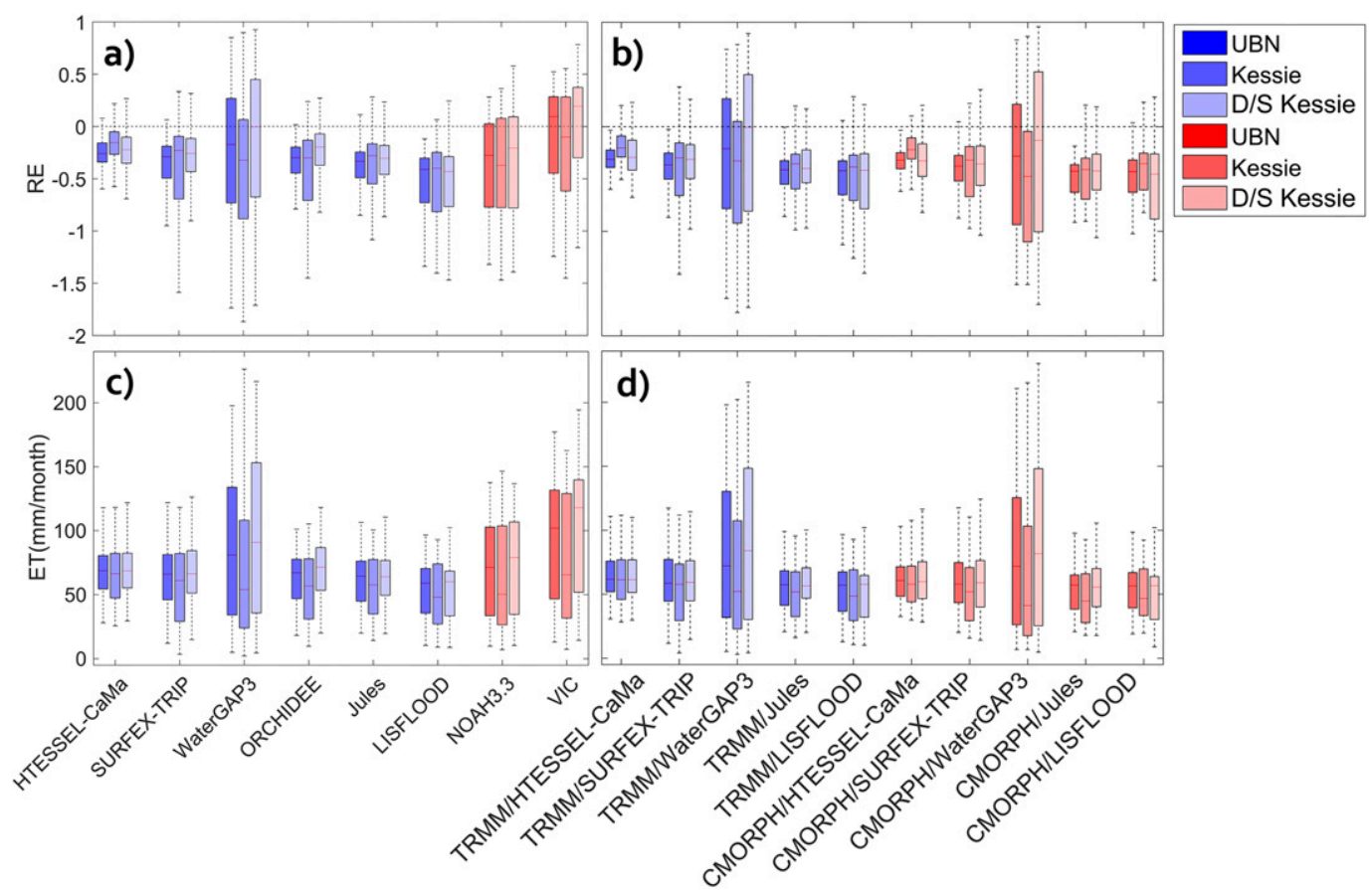

FIG. 5. As in Fig. 4 but for ET. The different colors correspond to different precipitation forcing. For (a) and (c) blue indicates the products with MSWEP forcing and red indicates CHIRPS. For (b) and (d), blue indicates the products with TRMM and red indicates CMORPH precipitation.

the lowest normalized centered RMSE (NCRMSE) (0.19 and 0.29 , respectively). In contrast to precipitation, ET estimates from some of the WRR products (WaterGAP3 VIC and Noah) showed correlation lower than 0.8 and NCRMSE higher than 1, mainly over the wetter basin. Moreover, we noted that most of the WRR products with satellite-derived precipitation forcing exhibited better performance statistics (correlation, NCRMSE, and SD) for ET than the blended precipitation forced data, although in terms of median of RE the opposite was the case. SURFEX-TRIP forced with CMORPH had the highest correlation with ET observations, at all three basin scales (with a correlation of 0.94 in the dry basin and 0.85 in the wet). In terms of NCRMSE, JULES forced with CMORPH had the best performance in the entire UBN (NCRMSE of 0.36) and Kessie (0.37) basins, and SURFEX-TRMM forced with TRMM exhibited the lowest NCRMSE (0.65) in the wetter region of the UBN basin. WaterGAP3 and VIC showed the poorest performance in terms of NCRMSE (higher than 1.5) and NSD (higher than 2.5) for the three basins.

In contrast to ET, streamflow estimates from all the WRR products exhibited correlation higher than 0.8, except for ORCHIDEE. Similar to the results for ET, the products with satellite-derived precipitation forcing were in closer agreement with the streamflow observations. Notable in these figures is that the WRR products, which provided better representation of streamflow, exhibited relatively poor performance in ET representation. Specifically, although WaterGAP3 exhibited the poorest performance in estimating ET, the opposite was true for streamflow. WaterGAP3 forced with all three different precipitation products showed the best performance for streamflow among the other models for the three basin scales. Specifically, the model with TRMM precipitation forcing data obtained correlations of $0.92,0.91$, and 0.83 in the entire UBN, the dry region, and the wet region, respectively, and NCRMSEs of 0.4 in the entire UBN, 0.37 in Kessie, and 0.6 in the wet basin. VIC also was in close agreement with the streamflow observations, with a correlation of 0.95 and NCRMSE of 0.16 in the UBN basin.

Figures 9-11 show the results of the water budget analysis for the UBN, Kessie, and D/S Kessie basins, respectively, providing the mean relative errors of precipitation, ET, and streamflow and anomalies of TWS estimates from the WRR products at annual scale. For this analysis, we compared the TWS anomalies estimated by the models using the GRACE terrestrial water storage anomalies dataset. As evident in the figures, all the WRR products underestimated TWS for the three spatial scales. VIC exhibited the lowest MRE for all four 

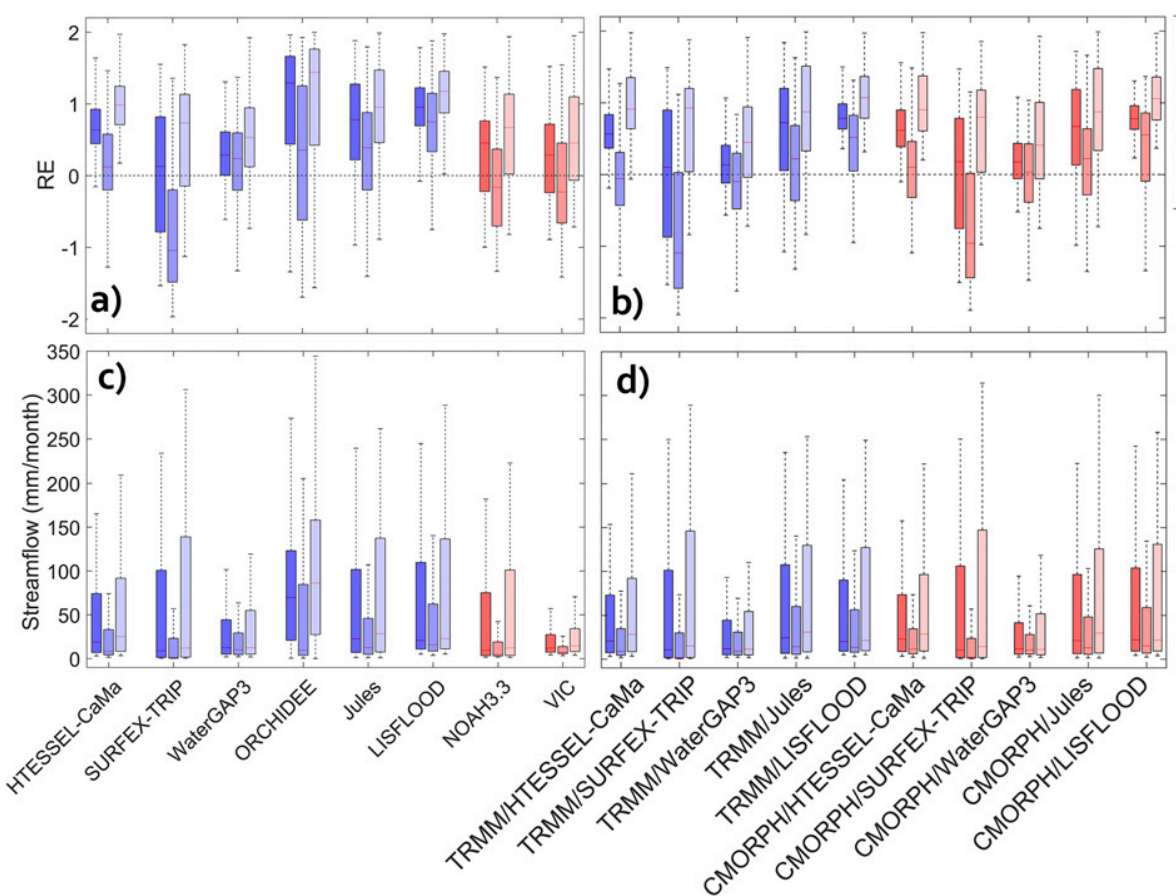

b)

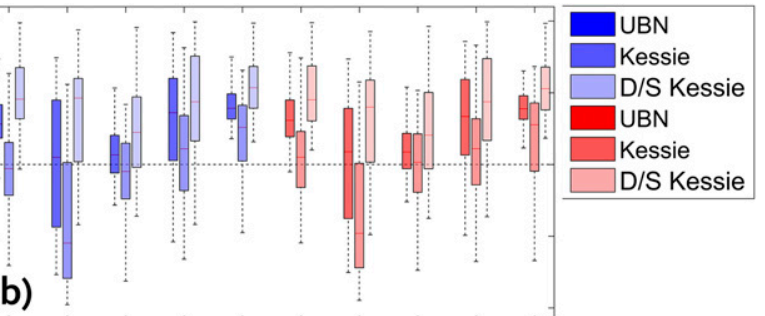

d)

FIG. 6. As in Fig. 5, but for streamflow.

water cycle components $(-0.066$ for TWS, -0.052 for precipitation, 0.86 for ET, and -0.233 for streamflow) for the entire UBN. Figure 10 shows that, for the dry (Kessie) basin, the MRE of TWS was higher [from -0.724 (HTESSEL-CaMa) to -1.931 (LISFLOOD)], despite the overall lower MRE of streamflow [from 0.009 (HTESSEL-CaMa) to 2.362 (ORCHIDEE)] and ET [from 0.015 (VIC) to -1 (LISFLOOD)] than that of the wet region of the UBN [MRE of TWS from -0.235 (VIC) to -1.393 (SURFEX-TRIP)]. HTESSEL-CaMa forced with MSWEP exhibited the best representation of all water cycle components for the Kessie basin $(-0.724$ for TWS, -0.089 for precipitation, -0.142 for ET, and 0.009 for streamflow) and VIC for the wet basin ( -0.235 for TWS, 0.089 for precipitation, 0.232 for ET, and -0.034 for streamflow). Moreover, we noted that, although WaterGAP3 had very low mean relative errors of precipitation, ET, and streamflow for the dry basin, this was not the case for TWS (up to -1.475).

Figures 12 and 13 and Table 2 present the TWS representation from the WRR products. Specifically, Figs. 11 and 12 show the time series of the monthly anomalies of TWS estimates from the WRR products for the entire UBN, Kessie, and D/S Kessie basins. Table 2 summarizes the R, RSD, and RMSE calculated for the monthly TWS estimates derived from the WRR products and the observed precipitation, ET, and streamflow data for each spatial scale. It is evident in both figures that the TWS estimates derived from the observed precipitation, ET, and streamflow data were in good agreement with the reference data (GRACE) for all basins ( $R$ of $0.77,0.59$, and 0.84 , RSD of $1.5,0.9$, and 1.11, and RMSE of 5.93, 7.65, and $5.31 \mathrm{~mm}$ in the entire UBN, Kessie, and D/S Kessie basins, respectively). Moreover, we noted a time lag of one month between the high peaks of all WRR products' time series and GRACE data during most of the years. Notable both from the figures and the table is that the WRR products with satellite-derived precipitation forcing exhibited better performance statistics for TWS estimates than the blended precipitation-forced data, with correlation up to 0.73 (HTESSEL-CaMa), RSD up to 0.88 (SURFEX-TRIP), and RMSE of $5.23 \mathrm{~cm}$ (HTESSEL-CaMa). VIC and HTESSEL-CaMa exhibited the best performance in terms of $R, \mathrm{RSD}$, and RMSE for all spatial scales.

Figure 14 shows the water budget residuals at monthly scale derived from the reference datasets, and Table 3 presents the standard deviation of the bias of the water cycle components (among the different products) and the water budget residuals. The water budget residual ranges from -126 to $158 \mathrm{~mm} \mathrm{month}^{-1}$ for the UBN basin, from -144 to $203 \mathrm{~mm}$ month $^{-1}$ for Kessie, and from -113 to $184 \mathrm{~mm} \mathrm{month}^{-1}$ for the wetter basin. The water budget residual shows an excess of water during the wet season 


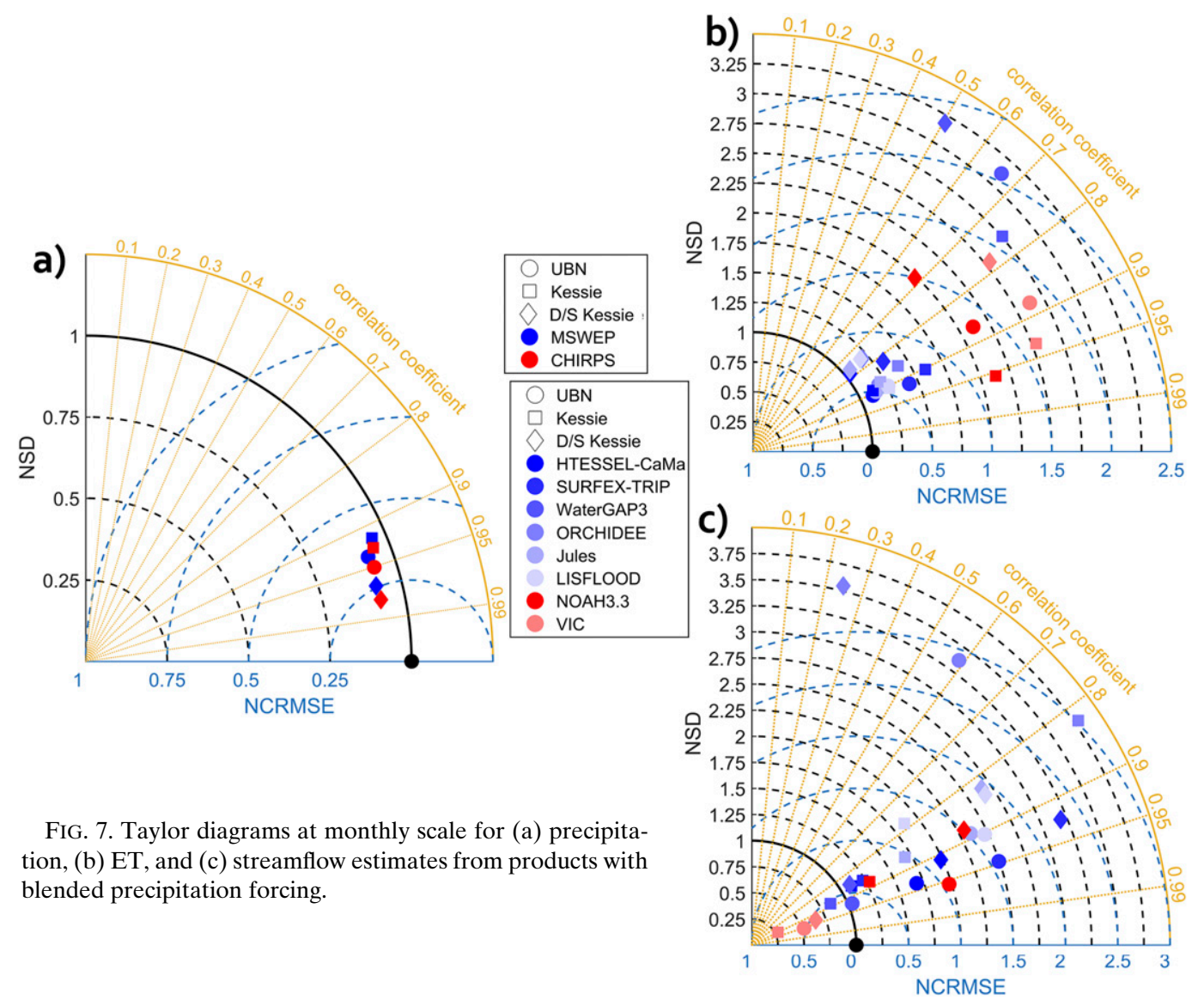

(from June to September) and negative residuals during the dry season. Moreover, as shown in Table 3, the variability of the residual values for all basins is much higher than the variability of the bias of precipitation, ET, streamflow, and the changes of TWS (among the products).

\section{Discussion}

The results of this analysis demonstrated the impact of different forcing data and land surface or hydrological modeling schemes on the representation of the water cycle components. Based on this study, uncertainty in the land surface hydrological simulations was dominated by the differences in modeling schemes rather than precipitation forcing. However, there are studies in other regions (Bhuiyan et al. 2018) that have shown that different precipitation datasets can strongly affect the hydrological simulations. As mentioned in the results, the four precipitation datasets used as forcing for the LSM and hydrological models were in close agreement with in situ observations. The uncertainty observed, mainly for the smaller Kessie basin, can be attributed to the basin's complex terrain. In mountainous regions, precipitation estimates from numerical weather prediction models are often associated with high uncertainty due to limitations in capturing certain types of precipitation, mainly because of spatial resolution constraints. Moreover, satellite-based rainfall products over complex terrain are generally susceptible to significant uncertainty (Stampoulis and Anagnostou 2012; Derin and Yilmaz 2014; Mei et al. 2014).

Our results showed an overall underestimation of ET from the WRR products for both basin scales. VIC, however, was the only model that overestimated ET in all basins. That overestimation might be attributed to the relatively low amount of streamflow (when compared with the other models). Also, the distribution of the ET values and REs for VIC and Noah might be partly attributed to the meteorological forcing, which is different from that of the other products. Moreover, we noted some differences (on the order of $35 \%$ in some cases) in the representation of ET between the WRR products with blended and satellite-derived precipitation forcing, respectively. Although the datasets with blended precipitation forcing achieved slightly lower relative errors, the data with satellite-based rainfall forcing showed better performance in terms 


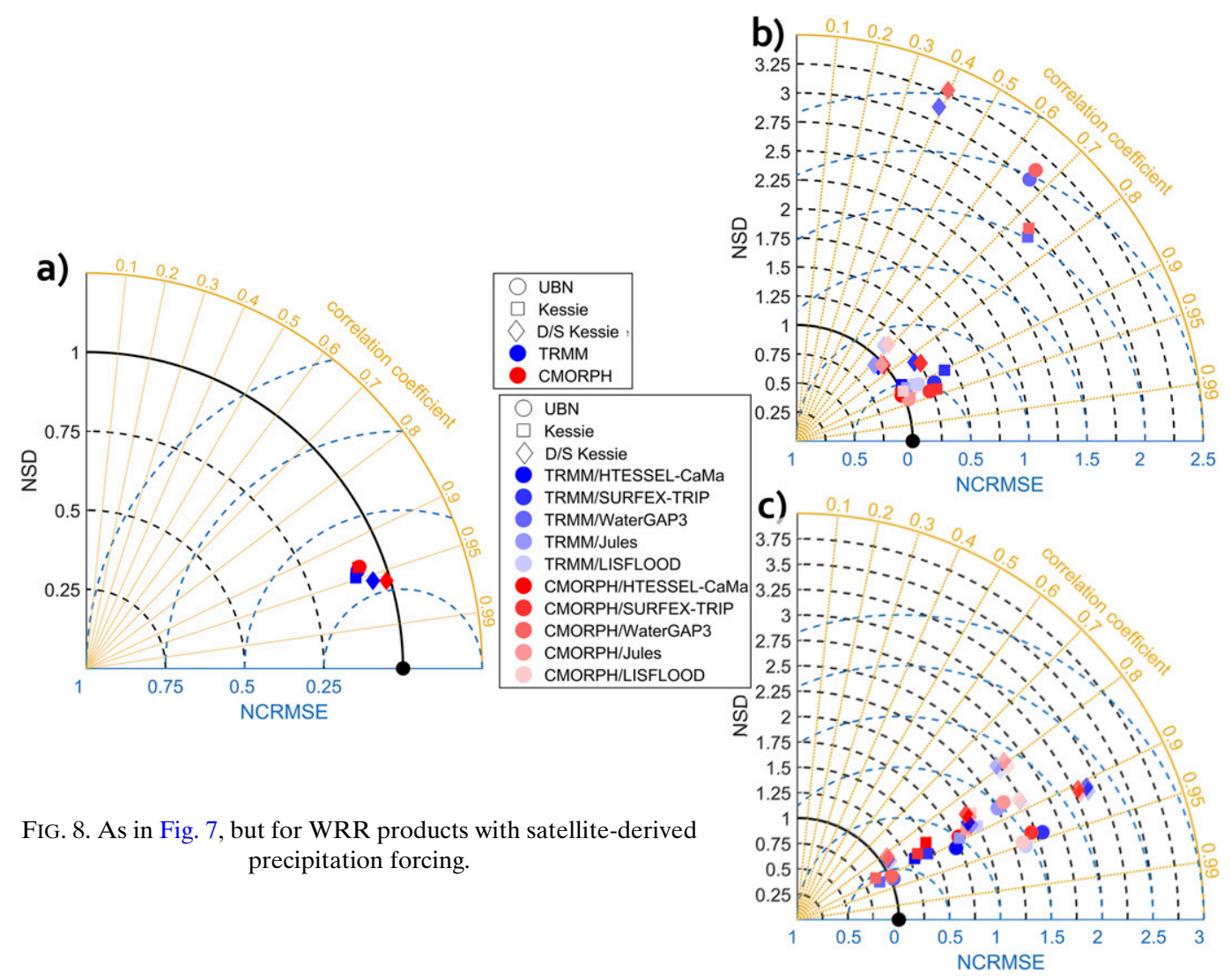

of NCRMSE, NSD, and correlation. This is an indication that different error properties of precipitation affect in different ways the error characteristics of ET. This finding is consistent with the results of other studies. Bhuiyan et al. (2018) pointed out in their study the complexity of precipitation error propagation in hydrological models and WRRs. The differences in the ET estimates between the products with different ET schemes were higher (WaterGAP3 and NOAH). This indicates that ET estimates are more sensitive to the differences between the schemes used by the models rather than the differences between the forcing variables.

In our analysis, most of the WRR products overestimated streamflow mainly for the larger basin, which was likely due to the underestimation of ET (given that the biases in precipitation were relatively low). This overestimation was consistent with the varying results of previous studies in the area (Siam et al. 2013; Jung et al. 2017). Similar to the results for ET, we noted small differences in the simulated water cycle parameters among the products driven with different precipitation datasets. However, we noted that the satellite-derived precipitation forcing exhibited better performance statistics for streamflow. Specifically, these products exhibited higher correlation, which implies a better representation of the streamflow dynamics at monthly scale. Moreover, the distribution of the relative errors showed lower bias and uncertainty than the products with blended precipitation forcing. In terms of annual MRE, however, in some models (WaterGAP3 and LISFLOOD) the mean annual streamflow magnitude was better represented with the satellite-derived precipitation forcing, while in other models (HTESSELCaMa, SURFEX-TRIP, JULES) the blended precipitation forcing gave a better representation. The lower relative errors in the TRMM precipitation-driven WRR product can be attributed to the precipitation underestimation of the TRMM product. Also, as with ET, the representation of streamflow (in terms of RE and MRE) in the drier (Kessie) basin is better than in the wet part and the entire UBN basin. This lower underestimation of streamflow might be attributed to the underestimation of precipitation in the dry basin.

Similar with ET, we noted high differences between the products with different runoff schemes. Specifically, ORCIDEE (which uses the Green-Ampt infiltration relationship) and WaterGAP3 exhibited the worst and 

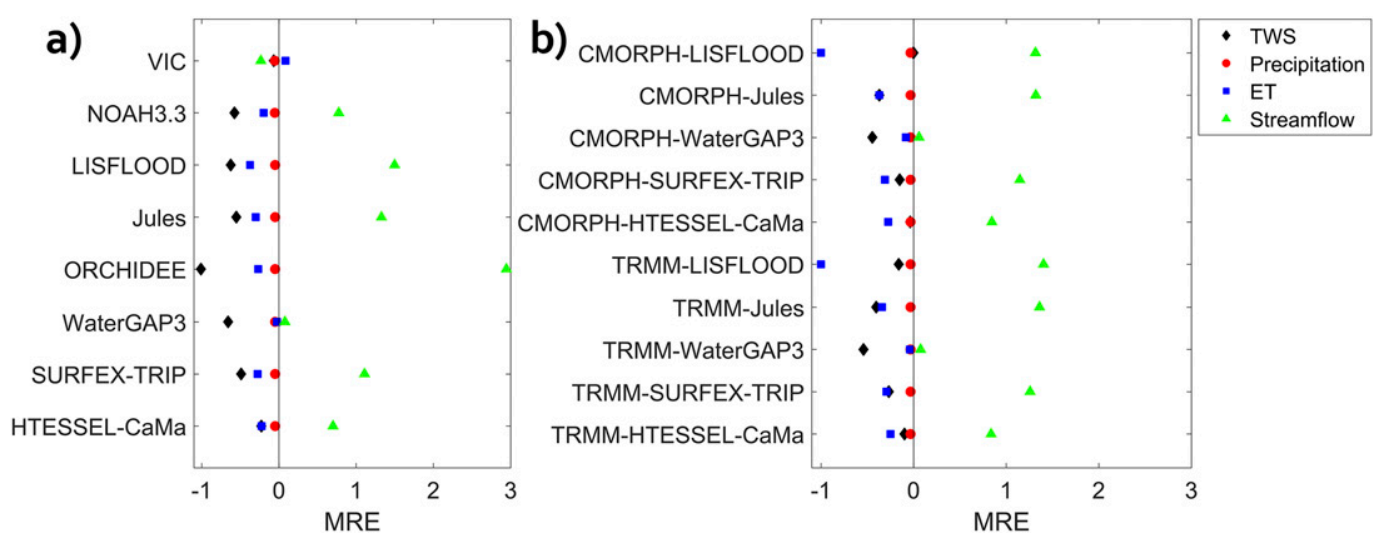

FIG. 9. Water budget analysis plot for UBN basin, showing mean relative errors of precipitation, ET, streamflow, and TWS estimates from products with (a) blended and (b) satellite-derived precipitation forcing.

best performances in streamflow, respectively. Moreover, there were products (SURFEX-TRIP, LISFLOOD, and JULES) with high correlation but high REs and NCRMSE (with all the three different precipitation forcings). This high correlation might be attributed to the high correlation of all the three precipitation forcings used for these models. As with ET, the error properties of precipitation affected (in different way) the error characteristics of streamflow. The high REs and NCRMSE might be attributed to the differences between the schemes used for these products. Therefore, similar to ET, uncertainty in streamflow simulations is dominated by the differences in modeling schemes rather than precipitation forcing.

As mentioned before, our analysis showed that WRR products (WaterGAP3 and VIC) that provided better representation of streamflow exhibited relatively poor performance in ET representation. WaterGAP3 and VIC are calibrated against measured river discharge. This calibration explains why these two models consistently outperformed others in streamflow representation. On the other hand, a message that emerges from these results is that, while calibration improves streamflow simulation, it results in a poorer (relative to other products) performance with respect to ET.

We noted in this study that TWS estimates from some of the WRR products agreed well with GRACE data. However, the precipitation, ET, and streamflow error propagation to the TWS estimates was evident. Given the better representation of ET and streamflow from the datasets with satellite-based rainfall forcing, TWS estimates from these datasets were in closer agreement with the GRACE data. Moreover, the products with better representation of ET (HTESSEL-CaMa, SURFEXTRIP, and JULES) achieved better representation of TWS, in terms of intra-annual dynamics (correlation) and interannual magnitude (MRE), which was expected, since ET plays an important role in the water budget in the region (Abera et al. 2017). VIC exhibited high performance of TWS, however (in terms of correlation, RSD,
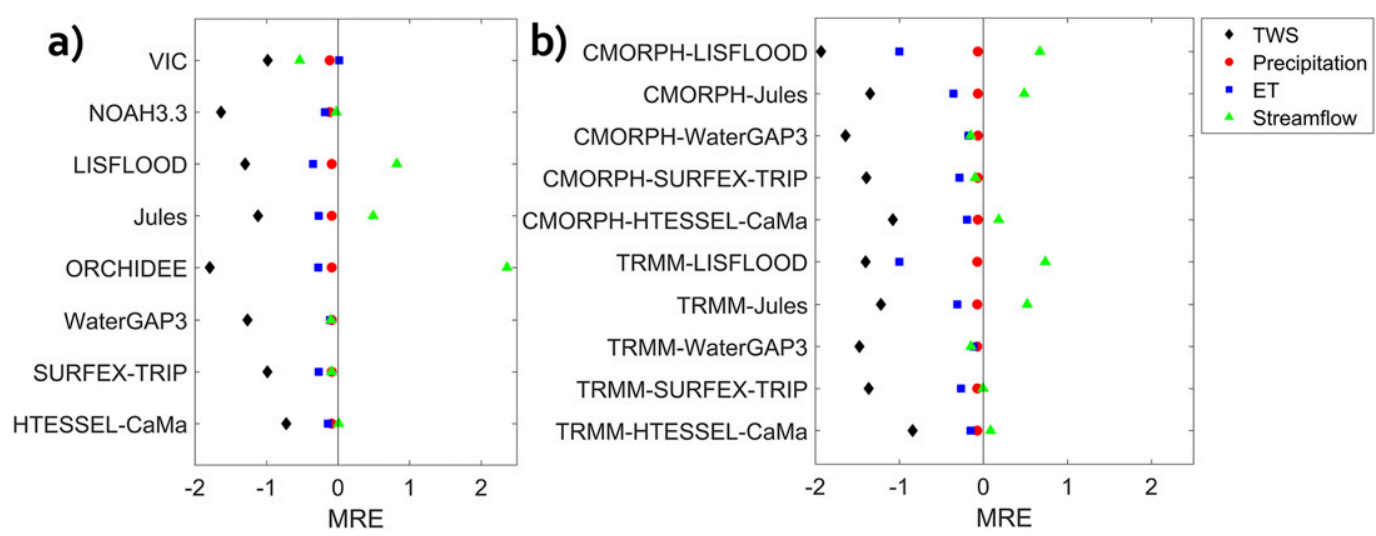

FIG. 10. As in Fig. 9, but for the Kessie basin. 
TABLE 2. Statistical evaluation of TWS estimates from the WRR products.

\begin{tabular}{|c|c|c|c|c|c|c|c|c|c|}
\hline & \multicolumn{3}{|c|}{$R$} & \multicolumn{3}{|c|}{ RSD } & \multicolumn{3}{|c|}{ RMSE $(\mathrm{cm})$} \\
\hline & UBN & Kessie & D/S Kessie & UBN & Kessie & D/S Kessie & UBN & Kessie & D/S Kessie \\
\hline Observations & 0.769 & 0.586 & 0.842 & 1.496 & 0.896 & 1.112 & 5.927 & 7.652 & 5.311 \\
\hline HTESSEL-CaMa & 0.719 & 0.645 & 0.744 & 0.839 & 0.653 & 0.668 & 5.462 & 6.635 & 6.030 \\
\hline SURFEX-TRIP & 0.513 & 0.543 & 0.466 & 0.847 & 0.664 & 0.719 & 7.184 & 7.501 & 8.641 \\
\hline WaterGap & 0.595 & 0.483 & 0.607 & 0.329 & 0.279 & 0.240 & 6.081 & 7.447 & 7.198 \\
\hline ORCHIDEE & 0.292 & -0.109 & 0.310 & 0.569 & 0.219 & 1.054 & 8.068 & 10.319 & 10.680 \\
\hline Jules & 0.652 & 0.560 & 0.698 & 0.376 & 0.317 & 0.288 & 5.744 & 7.041 & 6.582 \\
\hline LISFLOOD & 0.495 & 0.397 & 0.524 & 0.628 & 0.630 & 0.456 & 6.954 & 8.494 & 7.761 \\
\hline NOAH3.3 & 0.512 & 0.444 & 0.499 & 0.489 & 0.639 & 0.301 & 6.646 & 8.187 & 7.782 \\
\hline VIC & 0.740 & 0.587 & 0.786 & 1.107 & 0.809 & 0.940 & 5.608 & 7.371 & 5.786 \\
\hline TRMM/HTESSEL-CaMa & 0.725 & 0.674 & 0.746 & 0.756 & 0.523 & 0.642 & 5.325 & 6.289 & 5.986 \\
\hline TRMM/SURFEX-TRIP & 0.523 & 0.596 & 0.464 & 0.840 & 0.667 & 0.708 & 7.097 & 7.077 & 8.629 \\
\hline TRMM/WaterGap & 0.561 & 0.490 & 0.558 & 0.312 & 0.237 & 0.243 & 6.262 & 7.408 & 7.463 \\
\hline TRMM/Jules & 0.676 & 0.595 & 0.725 & 0.381 & 0.317 & 0.318 & 5.593 & 6.834 & 6.340 \\
\hline TRMM/LISFLOOD & 0.620 & 0.589 & 0.625 & 0.663 & 0.586 & 0.523 & 6.112 & 7.029 & 7.052 \\
\hline CMORPH/HTESSEL-CaMa & 0.731 & 0.645 & 0.763 & 0.711 & 0.481 & 0.665 & 5.231 & 6.505 & 5.812 \\
\hline CMORPH/SURFEX-TRIP & 0.546 & 0.558 & 0.515 & 0.879 & 0.676 & 0.804 & 6.993 & 7.397 & 8.410 \\
\hline CMORPH/WaterGap & 0.578 & 0.474 & 0.592 & 0.307 & 0.257 & 0.259 & 6.175 & 7.485 & 7.263 \\
\hline CMORPH/Jules & 0.670 & 0.558 & 0.730 & 0.358 & 0.293 & 0.342 & 5.638 & 7.054 & 6.261 \\
\hline CMORPH/LISFLOOD & 0.652 & 0.455 & 0.598 & 0.665 & 0.591 & 0.516 & 5.869 & 8.019 & 7.267 \\
\hline
\end{tabular}

RMSE, and MRE), despite the relatively poor performance on ET (mainly in terms of uncertainty-given by the distribution of the REs-and correlation). This may be because it was the only model that underestimated streamflow and overestimated ET, resulting in smaller underestimation of TWS. We noted that high overestimation of streamflow combined with very high underestimation of ET resulted in lower underestimation of TWS; this was the case for LISFLOOD. We also noted that all the WRR products obtained higher performance in the entire UBN basin and the wetter region than the smaller basin. This may be partly attributable to uncertainties in GRACE data related to the spatial extent of the basins, since the area of the Kessie and the wetter basin is much smaller than the minimum area that can be resolved by GRACE.
In addition, with regard to TWS representation from the WRR products, we noted that the high peaks of GRACE anomalies lagged by one month the TWS anomalies derived from the observations and WRR data - a time lag also observed by Jung et al. (2017) in the TWS estimates derived by NOAH3.3 forced with meteorology form MERRA-2. They attributed this time lag to the fact that NOAH3.3 underestimated ET during the winter season and produced higher streamflow peak value earlier than the other models they used in their study. In our study, we saw an underestimation of ET during the winter only in VIC, NOAH3.3, and WaterGAP3, but we did not notice an earlier high peak of streamflow in these models. This time lag may be due to the direct response of precipitation, ET, and streamflow (used for the TWS estimates in these studies), as compared to the slower
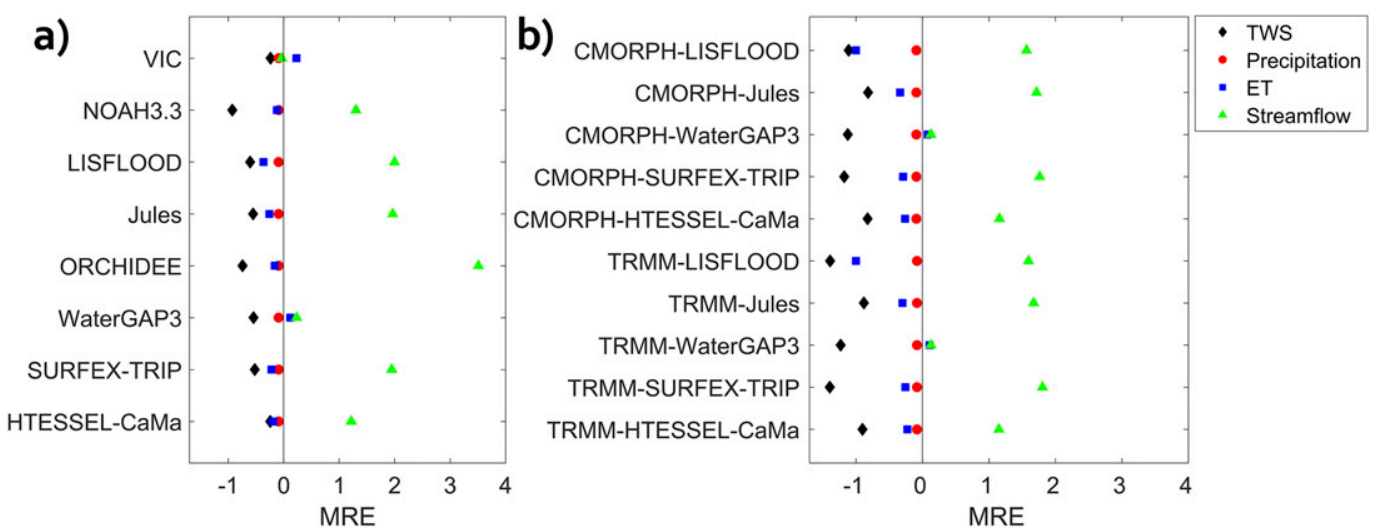

FIG. 11. As in Fig. 9, but for the D/S Kessie basin. 


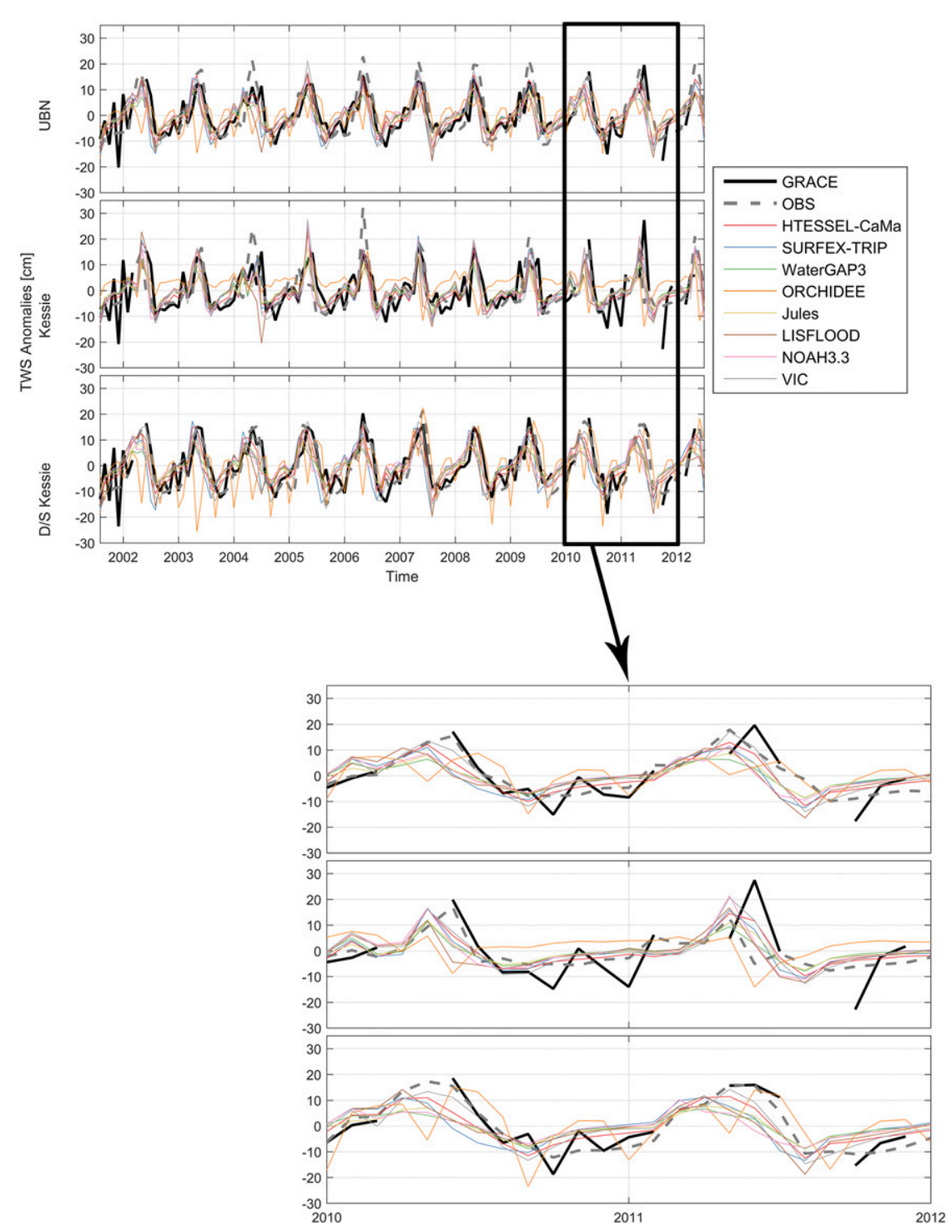

FIG. 12. Anomalies of TWS estimates from products with blended precipitation forcing over the two basins.

response of the other states of the water cycle-soil moisture, groundwater, and so on-that affect TWS. Awange et al. (2014) conducted a correlation analysis using mean monthly data to study the time lags between TWS and, respectively, soil moisture and rainfall. They observed lags of 0 to 6 months between rainfall and TWS. They stated that the longer lag periods were indicative of large groundwater reservoirs, indirect recharge mechanisms, or a combination of both.

Last, the imbalance analysis implies high uncertainty associated with the observations. In this study, we used in situ observations for precipitation and streamflow; therefore, uncertainties are mainly associated with ET and terrestrial water storage. More specifically, uncertainties of satellite-derived ET are a combination of the errors of the meteorological input data and the errors introduced by the model (Ferguson et al. 2010). Moreover, the GRACE data include measurement and leakage errors (Landerer and Swenson 2012). To reduce the uncertainty of the reference datasets, integration techniques that apply water budget closure correction models need to be applied as postprocessing tools. There are several studies (Munier et al. 2014; Pan et al. 2012; Sheffield et al. 2009; Aires 2014; Rodell et al. 2015) proposing water budget closure methods for water cycle component datasets, such as simple weighting, constrained linear, optimal interpolation, postprocessing filtering, and neural networks. 


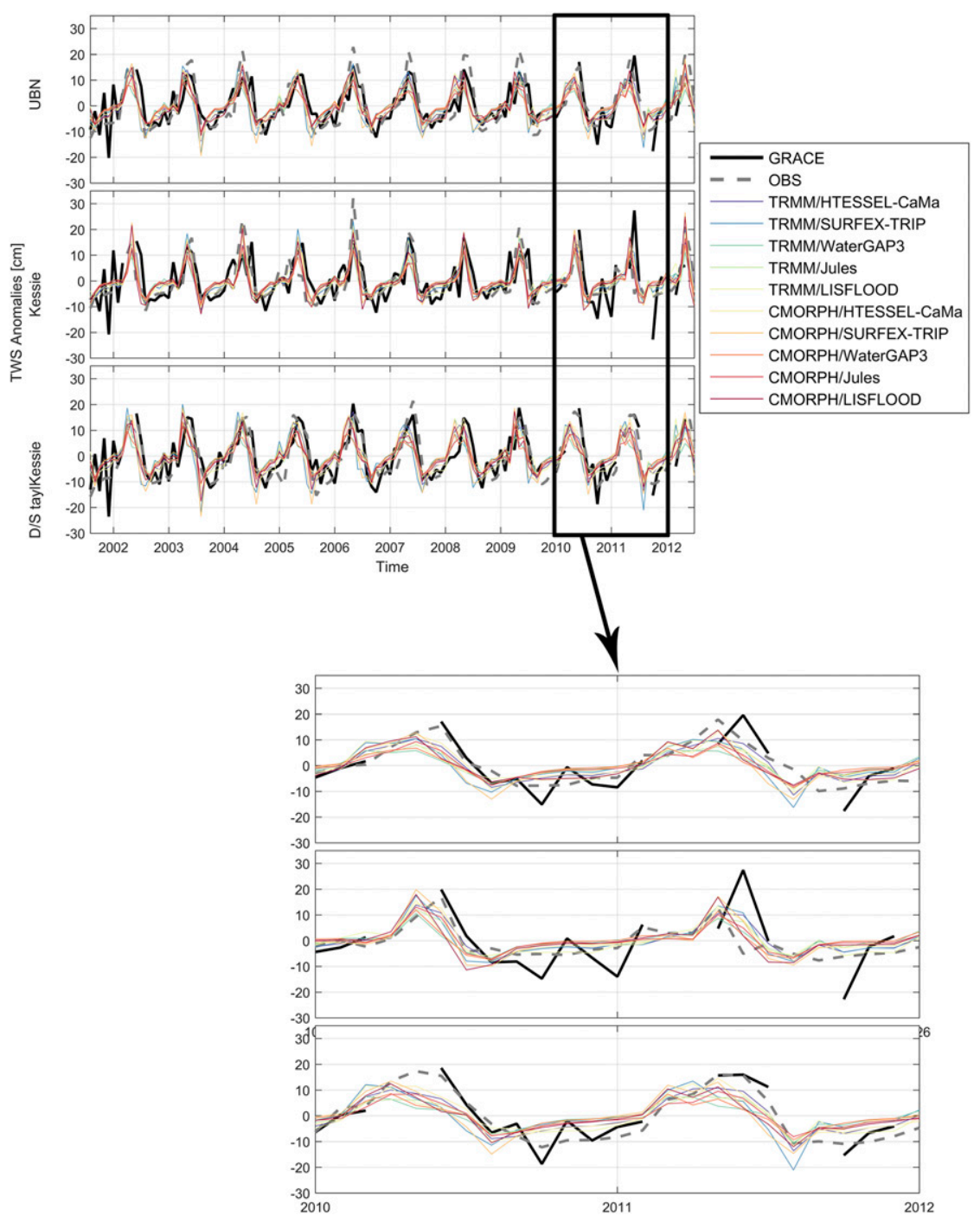

FIG. 13. As in Fig. 12, but for satellite-derived precipitation forcing data.

\section{Conclusions}

We performed an evaluation of 18 WRR products to study the uncertainty of the water cycle representation in the UBN basin based on different combinations of land surface/hydrological models and atmospheric forcing datasets. Specifically, we statistically evaluated errors in individual water cycle parameters (monthly scale) represented in the different WRR products, and their annual water budget over three basins in the UBN.

We found that the uncertainty in the estimation of the water cycle components from different reanalysis products is mainly attributable to the differences in the schemes used by the various LSMs, while variations of precipitation forcing have lesser impact on the performance of the WRR products, as exhibited by the small differences among the datasets produced with the same model but different precipitation forcing datasets.

We did not identify a single product that would consistently outperform others. Our results showed an overall underestimation of ET and TWS and an overestimation of streamflow by all WRR products at the

TABLE 3. Standard deviation of the bias of the water cycle components and the water budget residuals for the three basins.

\begin{tabular}{|c|c|c|c|}
\hline & $\mathrm{UBN}$ & Kessie & D/S Kessie \\
\hline $\begin{array}{l}\text { Water budget residual } \\
\left(\mathrm{mm} \mathrm{month}^{-1}\right)\end{array}$ & 83.3886 & 92.1388 & 172.5801 \\
\hline$P$ bias (mm month $\left.{ }^{-1}\right)$ & 12.4635 & 12.0404 & 19.3114 \\
\hline ET bias (mm month $\left.{ }^{-1}\right)$ & 18.3607 & 31.2098 & 22.5594 \\
\hline$Q$ bias $\left(\mathrm{mm}\right.$ month $\left.{ }^{-1}\right)$ & 24.8657 & 20.4191 & 31.3839 \\
\hline$\Delta$ TWS bias $\left(\mathrm{mm}\right.$ month $\left.^{-1}\right)$ & 5.8831 & 7.4438 & 6.5905 \\
\hline
\end{tabular}




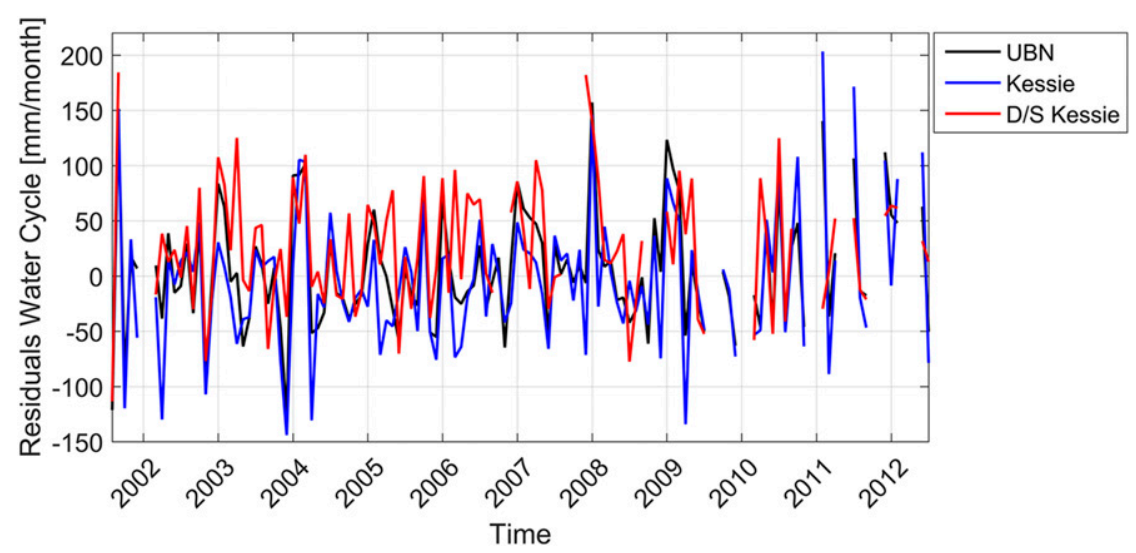

FIG. 14. Monthly water budget residuals derived from the reference datasets for the three basins.

three basin scales examined. Moreover, we noted that WRR products that provided better representation of streamflow (WaterGAP3 and VIC) were those that included calibration against historical streamflow observations; however, these products exhibited relatively poor performance in ET representation. Additionally, the precipitation, ET, and streamflow error propagation to the TWS estimates was evident. TWS estimates from the products with better representation of ET were in closer agreement with the observations.

Our results highlight the importance of calibration on hydrological applications, such as reservoir management, and that WaterGAP3 and VIC should be considered as the top candidates among those examined. Moreover, for applications where ET and TWS play an important role, such as agriculture, the most suitable products are SURFEX-TRIP and JULES, which provided more accurate ET estimates, and HTESSELCaMa and VIC, which exhibited the best representation of TWS. Overall, while the results of this study demonstrated some large discrepancies within WRR estimates, it was also presented that many of the products have still significant skill in representing variability of water cycle components. This suggests that further postprocessing procedures (e.g., bias correction, ensemble averaging techniques, etc.) could be considered to further exploit the long-term information provided from such products.

In addition, the high water budget residuals from the reference datasets suggest that postprocessing integration techniques should be applied to the observations. Moreover, the high variability between the estimates of the water cycle components (especially streamflow, ET, and TWS) of the WRR datasets used in this study could be used as uncertainty estimates for these integration techniques.
The findings from this study provide an example that elucidates the current strengths and limitations of available WRR datasets in analyzing the water cycle components of the upper Blue Nile basin, an area that exhibits water and food insecurities associated with significant hydroclimatic variability. Our future studies are intended to continue improving our understanding of hydrological processes, in regions where hydrological observations are sparse, based on locally calibrated high-resolution distributed hydrological and groundwater modeling that can provide essential information for water security and management.

Acknowledgments. This material is based upon work supported by the National Science Foundation under Grant 1545874. The authors thank the Ethiopian Ministry of Water, Irrigation, and Energy, the National Meteorological Agency, and the Abbay Basin Authority for kindly providing access to the in situ observations used in this work. We also thank EartH2Observe (www.earth2observe.org) for providing their final water resource reanalysis dataset and NASA for providing their VIC reanalysis data over the upper Blue Nile area.

\section{REFERENCES}

Abera, W., G. Formetta, L. Brocca, and R. Rigon, 2017: Modeling the water budget of the upper Blue Nile basin using the JGrassNewAge model system and satellite data. Hydrol. Earth Syst. Sci., 21, 3145-3165, https://doi.org/10.5194/hess-21-3145-2017.

Aires, F., 2014: Combining datasets of satellite-retrieved products. Part I: Methodology and water budget closure. J. Hydrometeor., 15, 1677-1691, https://doi.org/10.1175/JHM-D-13-0148.1.

Allam, M. M., A. Jain Figueroa, D. B. McLaughlin, and E. A. Eltahir, 2016: Estimation of evaporation over the upper Blue Nile basin by combining observations from satellites and river flow gauges. Water Resour. Res., 52, 644-659, https://doi.org/ 10.1002/2015WR017251. 
Awange, J. L., M. Gebremichael, E. Forootan, G. Wakbulcho, R. Anyah, V. G. Ferreira, and T. Alemayehu, 2014: Characterization of Ethiopian mega hydrogeological regimes using GRACE, TRMM and GLDAS datasets. Adv. Water Resour., 74, 64-78, https:// doi.org/10.1016/j.advwatres.2014.07.012.

Balsamo, G., A. Beljaars, K. Scipal, P. Viterbo, B. van den Hurk, M. Hirschi, and A. K. Betts, 2009: A revised hydrology for the ECMWF model: Verification from field site to terrestrial water storage and impact in the Integrated Forecast System. J. Hydrometeor., 10, 623-643, https://doi.org/10.1175/ 2008JHM1068.1.

__- and Coauthors, 2015: ERA-Interim/Land: A global land surface reanalysis data set. Hydrol. Earth Syst. Sci., 19, 389-407, https://doi.org/10.5194/hess-19-389-2015.

Beck, H. E., A. I. Van Dijk, V. Levizzani, J. Schellekens, D. Gonzalez Miralles, B. Martens, and A. De Roo, 2017: MSWEP: 3-hourly $0.25^{\circ}$ global gridded precipitation (1979-2015) by merging gauge, satellite, and reanalysis data. Hydrol. Earth Syst. Sci., 21, 589615, https://doi.org/10.5194/hess-21-589-2017.

Best, M. J., and Coauthors, 2011: The Joint UK Land Environment Simulator (JULES), model description-Part 1: Energy and water fluxes. Geosci. Model Dev., 4, 677-699, https://doi.org/ 10.5194/gmd-4-677-2011.

Bhuiyan, M. A. E., and Coauthors, 2018: Assessment of precipitation error propagation in multi-model global water resources reanalysis. Hydrol. Earth Syst. Sci. Discuss., 23, 1973-1994, https://doi.org/10.5194/HESS-23-1973-2019.

Bosilovich, M. G., R. Lucchesi, and M. Suarez, 2015: MERRA-2: File specification. GMAO Office Note 9 (version 1.0), 73 pp., https://ntrs.nasa.gov/archive/nasa/casi.ntrs.nasa.gov/ 20150019760.pdf.

Burek, P., J. van der Kniff, and A. de Roo, 2013: LISFLOOD distributed water balance and flood simulation model: Revised user manual. JRC Tech. Rep., 139 pp.

Clark, D. B., and Coauthors, 2011: The Joint UK Land Environment Simulator (JULES), model description-Part 2: Carbon fluxes and vegetation dynamics. Geosci. Model Dev., 4, 701-722, https://doi.org/10.5194/gmd-4-701-2011.

Conway, D., 2000: The climate and hydrology of the upper Blue Nile River. Geogr. J., 166, 49-62, https://doi.org/10.1111/ j.1475-4959.2000.tb00006.x.

_ 2005: From headwater tributaries to international river: Observing and adapting to climate variability and change in the Nile basin. Global Environ. Change, 15, 99-114, https:// doi.org/10.1016/j.gloenvcha.2005.01.003.

Derin, Y., and K. K. Yilmaz, 2014: Evaluation of multiple satellite-based precipitation products over complex topography. J. Hydrometeor., 15, 1498-1516, https://doi.org/10.1175/ JHM-D-13-0191.1.

Döll, P., K. Fiedler, and J. Zhang, 2009: Global-scale analysis of river flow alterations due to water withdrawals and reservoirs. Hydrol. Earth Syst. Sci., 13, 2413-2432, https://doi.org/10.5194/ hess-13-2413-2009.

Ek, M. B., K. E. Mitchell, Y. Lin, E. Rogers, P. Grunmann, V. Koren, G. Gayno, and J. D. Tarpley, 2003: Implementation of Noah land surface model advances in the National Centers for Environmental Prediction operational mesoscale Eta model. J. Geophys. Res., 108, 8851, https://doi.org/10.1029/2002JD003296.

Eltahir, E. A., 1996: El Niño and the natural variability in the flow of the Nile River. Water Resour. Res., 32, 131-137, https:// doi.org/10.1029/95WR02968.

Fekete, B. M., C. J. Vörösmarty, J. O. Roads, and C. J. Willmott, 2004: Uncertainties in precipitation and their impacts on runoff estimates. J. Climate, 17, 294-304, https://doi.org/ 10.1175/1520-0442(2004)017<0294:UIPATI >2.0.CO;2.

Ferguson, C. R., J. Sheffield, E. F. Wood, and H. Gao, 2010: Quantifying uncertainty in a remote sensing-based estimate of evapotranspiration over continental USA. Int. J. Remote Sens., 31, 3821-3865, https://doi.org/10.1080/01431161.2010.483490.

Flörke, M., E. Kynast, I. Bärlund, S. Eisner, F. Wimmer, and J. Alcamo, 2013: Domestic and industrial water uses of the past 60 years as a mirror of socio-economic development: A global simulation study. Global Environ. Change, 23, 144-156, https://doi.org/10.1016/j.gloenvcha.2012.10.018.

Funk, C., and Coauthors, 2015: The climate hazards infrared precipitation with stations-A new environmental record for monitoring extremes. Sci. Data, 2, 150066, https://doi.org/ 10.1038/sdata.2015.66.

Gebremicael, T. G., Y. A. Mohamed, G. D. Betrie, P. van der Zaag, and E. Teferi, 2013: Trend analysis of runoff and sediment fluxes in the upper Blue Nile basin: A combined analysis of statistical tests, physically-based models and landuse maps. J. Hydrol., 482, 57-68, https://doi.org/10.1016/j.jhydrol.2012.12.023.

Getirana, A. C., J. C. V. Espinoza, J. Ronchail, and O. C. Rotunno Filho, 2011: Assessment of different precipitation datasets and their impacts on the water balance of the Negro River basin. J. Hydrol., 404, 304-322, https://doi.org/10.1016/ j.jhydrol.2011.04.037.

Grabs, W., 2009: Bridging the observational gap. Water in a Changing World, UN World Water Development Rep. 3, 226236, https://unesdoc.unesco.org/ark:/48223/pf0000181993.

Hirschi, M., S. I. Seneviratne, and C. Schär, 2006: Seasonal variations in terrestrial water storage for major midlatitude river basins. J. Hydrometeor., 7, 39-60, https://doi.org/10.1175/JHM480.1.

Jankov, I., W. A. Gallus Jr., M. Segal, B. Shaw, and S. E. Koch, 2005: The impact of different WRF Model physical parameterizations and their interactions on warm season MCS rainfall. Wea. Forecasting, 20, 1048-1060, https://doi.org/10.1175/WAF888.1.

Jung, H. C., A. Getirana, F. Policelli, A. McNally, K. R. Arsenault, S. Kumar, T. Tadesse, and C. D. Peters-Lidard, 2017: Upper Blue Nile basin water budget from a multimodel perspective. J. Hydrol., 555, 535-546, https://doi.org/ 10.1016/j.jhydrol.2017.10.040.

Kärnä, T., and A. M. Baptista, 2016: Evaluation of a long-term hindcast simulation for the Columbia River estuary. Ocean Modell., 99, 1-14, https://doi.org/10.1016/j.ocemod.2015.12.007.

Krinner, G., and Coauthors, 2005: A dynamic global vegetation model for studies of the coupled atmosphere-biosphere system. Global Biogeochem. Cycles, 19, GB1015, https://doi.org/ 10.1029/2003GB002199.

Landerer, F. W., and S. C. Swenson, 2012: Accuracy of scaled GRACE terrestrial water storage estimates. Water Resour. Res., 48, W04531, https://doi.org/10.1029/2011WR011453.

Liang, X., D. P. Lettenmaier, E. F. Wood, and S. J. Burges, 1994: A simple hydrologically based model of land surface water and energy fluxes for general circulation models. J. Geophys. Res., 99, 14 415-14 428, https://doi.org/10.1029/94JD00483.

Masson, V., and Coauthors, 2013: The SURFEXv7. 2 land and ocean surface platform for coupled or offline simulation of earth surface variables and fluxes. Geosci. Model Dev., 6, 929-960, https://doi.org/10.5194/gmd-6-929-2013.

McNally, A., and Coauthors, 2017: A land data assimilation system for sub-Saharan Africa food and water security applications. Sci. Data, 4, 170012, https://doi.org/10.1038/sdata.2017.12.

Mei, Y., E. N. Anagnostou, E. I. Nikolopoulos, and M. Borga, 2014: Error analysis of satellite precipitation products in 
mountainous basins. J. Hydrometeor., 15, 1778-1793, https:// doi.org/10.1175/JHM-D-13-0194.1.

Melesse, A. M., W. Abtew, S. G. Setegn, and T. Dessalegne, 2011: Hydrological variability and climate of the upper Blue Nile River basin. Nile River Basin, Springer, 3-37.

Mokria, M., A. Gebrekirstos, A. Abiyu, M. Van Noordwijk, and A. Bräuning, 2017: Multi-century tree-ring precipitation record reveals increasing frequency of extreme dry events in the upper Blue Nile River catchment. Global Change Biol., 23, 5436-5454, https://doi.org/10.1111/gcb.13809.

Munier, S., F. Aires, S. Schlaffer, C. Prigent, F. Papa, P. Maisongrande, and M. Pan, 2014: Combining data sets of satellite-retrieved products for basin-scale water balance study: 2. Evaluation on the Mississippi Basin and closure correction model. J. Geophys. Res. Atmos., 119, 12 100-12 116, https://doi.org/ 10.1002/2014JD021953.

Pan, M., A. K. Sahoo, T. J. Troy, R. K. Vinukollu, J. Sheffield, and E. F. Wood, 2012: Multisource estimation of long-term terrestrial water budget for major global river basins. J. Climate, 25, 3191-3206, https://doi.org/10.1175/JCLI-D-11-00300.1.

Rientjes, T. H. M., A. T. Haile, E. Kebede, C. M. M. Mannaerts, E. Habib, and T. S. Steenhuis, 2011: Changes in land cover, rainfall and stream flow in Upper Gilgel Abbay catchment, Blue Nile basin-Ethiopia. Hydrol. Earth Syst. Sci., 15, 1979 1989, https://doi.org/10.5194/hess-15-1979-2011.

Rodell, M., and Coauthors, 2015: The observed state of the water cycle in the early twenty-first century. J. Climate, 28, 82898318, https://doi.org/10.1175/JCLI-D-14-00555.1.

_ J. S. Famiglietti, D. N. Wiese, J. T. Reager, H. K. Beaudoing, F. W. Landerer, and M. H. Lo, 2018: Emerging trends in global freshwater availability. Nature, 557, 651-659, https://doi.org/ 10.1038/s41586-018-0123-1.

Sahlu, D., E. I. Nikolopoulos, S. A. Moges, E. N. Anagnostou, and D. Hailu, 2016: First evaluation of the Day-1 IMERG over the upper Blue Nile basin. J. Hydrometeor., 17, 2875-2882, https:// doi.org/10.1175/JHM-D-15-0230.1.

Schellekens, J., and Coauthors, 2017: A global water resources ensemble of hydrological models: The eartH2Observe Tier-1 dataset. Earth Syst. Sci. Data, 9, 389-413, https://doi.org/ 10.5194/essd-9-389-2017.

Shamsudduha, M., R. G. Taylor, D. Jones, L. Longuevergne, M. Owor, and C. Tindimugaya, 2017: Recent changes in terrestrial water storage in the upper Nile basin: An evaluation of commonly used gridded GRACE products. Hydrol. Earth Syst. Sci., 21, 4533-4549, https://doi.org/10.5194/hess-21-4533-2017.

Sheffield, J., C. R. Ferguson, T. J. Troy, E. F. Wood, and M. F. McCabe, 2009: Closing the terrestrial water budget from satellite remote sensing. Geophys. Res. Lett., 36, L07403, https:// doi.org/10.1029/2009GL037338.

Siam, M. S., and E. A. Eltahir, 2015: Explaining and forecasting interannual variability in the flow of the Nile River. Hydrol. Earth Syst. Sci., 19, 1181-1192, https://doi.org/10.5194/hess-19-1181-2015. , M. E. Demory, and E. A. Eltahir, 2013: Hydrological cycles over the Congo and upper Blue Nile basins: Evaluation of general circulation model simulations and reanalysis products. J. Climate, 26, 8881-8894, https://doi.org/10.1175/JCLI-D-12-00404.1.
Stampoulis, D., and E. N. Anagnostou, 2012: Evaluation of global satellite rainfall products over continental Europe. J. Hydrometeor., 13, 588-603, https://doi.org/10.1175/JHM-D-11-086.1.

Swenson, S., D. Chambers, and J. Wahr, 2008: Estimating geocenter variations from a combination of GRACE and ocean model output. J. Geophys. Res., 113, B08410, https://doi.org/ 10.1029/2007JB005338.

Taye, M. T., and P. Willems, 2011: Influence of climate variability on representative QDF predictions of the upper Blue Nile Basin. J. Hydrol., 411, 355-365, https://doi.org/10.1016/j.jhydrol.2011.10.019.

Taylor, K. E., 2001: Summarizing multiple aspects of model performance in a single diagram. J. Geophys. Res., 106, 71837192, https://doi.org/10.1029/2000JD900719.

Teferi, E., S. Uhlenbrook, W. Bewket, J. Wenninger, and B. Simane, 2010: The use of remote sensing to quantify wetland loss in the Choke Mountain range, upper Blue Nile basin, Ethiopia. Hydrol. Earth Syst. Sci., 14, 2415-2428, https://doi.org/10.5194/ hess-14-2415-2010.

Tegegne, G., D. K. Park, and Y. O. Kim, 2017: Comparison of hydrological models for the assessment of water resources in a data-scarce region, the upper Blue Nile River basin. J. Hydrol. Reg. Stud., 14, 49-66, https://doi.org/10.1016/j.ejrh.2017.10.002.

Tekleab, S., S. Uhlenbrook, Y. Mohamed, H. H. G. Savenije, M. Temesgen, and J. Wenninger, 2011: Water balance modeling of upper Blue Nile catchments using a top-down approach. Hydrol. Earth Syst. Sci., 15, 2179-2193, https://doi.org/ 10.5194/hess-15-2179-2011.

Uhlenbrook, S., Y. Mohamed, and A. S. Gragne, 2010: Analyzing catchment behavior through catchment modeling in the Gilgel Abay, upper Blue Nile River basin, Ethiopia. Hydrol. Earth Syst. Sci., 14, 2153-2165, https://doi.org/10.5194/hess-14-2153-2010.

Wahr, J., and S. Zhong, 2013: Computations of the viscoelastic response of a 3-D compressible Earth to surface loading: An application to Glacial Isostatic Adjustment in Antarctica and Canada. Geophys. J. Int., 192, 557-572, https://doi.org/10.1093/GJI/GGS030.

Yen, H., X. Wang, D. G. Fontane, R. D. Harmel, and M. Arabi, 2014: A framework for propagation of uncertainty contributed by parameterization, input data, model structure, and calibration/validation data in watershed modeling. Environ. Modell. Software, 54, 211 221, https://doi.org/10.1016/j.envsoft.2014.01.004.

Zeng, N., J. H. Yoon, A. Mariotti, and S. Swenson, 2008: Variability of basin-scale terrestrial water storage from a PER water budget method: The Amazon and the Mississippi. J. Climate, 21, 248265, https://doi.org/10.1175/2007JCLI1639.1.

Zhang, K., J. S. Kimball, Q. Mu, L. A. Jones, S. J. Goetz, and S. W. Running, 2009: Satellite based analysis of northern ET trends and associated changes in the regional water balance from 1983 to 2005. J. Hydrol., 379, 92-110, https://doi.org/10.1016/ j.jhydrol.2009.09.047.

$\longrightarrow,-$, R. R. Nemani, and S. W. Running, 2010: A continuous satellite-derived global record of land surface evapotranspiration from 1983 to 2006. Water Resour. Res., 46, W09522, https://doi.org/10.1029/2009WR008800.

Y. Hong, J. J. Gourley, and Z. Yu, 2015: Vegetation greening and climate change promote multidecadal rises of global land evapotranspiration. Sci. Rep., $\mathbf{5}$, 15956, https://doi.org/10.1038/srep15956. 